The Korean Economic Review

Volume 32, Number 1, Summer 2016, 101-136.

\title{
Macroeconomic Shocks and Dynamics of Labor Markets in Korea*
}

\author{
Tae Bong Kim*** Hangyu Lee***
}

\begin{abstract}
A New Keynesian model with labor friction, in which involuntary unemployment can be endogenized, is estimated with the Korean macroeconomic data using a Bayesian estimation approach. The model is extended by specifying a small open economy with tradable and nontradable goods sectors to characterize the Korean labor market empirically. Results of empirical analyses based on the estimated model can be summarized as follows. First, the sectoral reallocation of labor plays an important role in the adjustment of the Korean labor market, which responds to macroeconomic shocks, particularly foreign shocks. Second, the historical decomposition analysis demonstrates that the cyclical fluctuations of unemployment in Korea are explained by key domestic shocks, such as domestic productivity shocks and preference shocks. A relatively small contribution of foreign shocks to aggregate labor market variables is partly caused by the sectoral shift of employment rather than extensive changes in aggregate employment and labor force.
\end{abstract}

JEL Classification: F41, E24, E32

Keywords: Small Open Economy, Labor Market, Macroeconomic Shocks, Employment Rate

\footnotetext{
Received: Aug. 6, 2015. Revised: March 22, 2016. Accepted: May 16, 2016.

* The authors are grateful to all seminar participants at the Bank of Korea, 2016 Korea's Allied Economic Association Annual Meeting, Yonsei University, Sungkyunkwan University, and Kyung Hee University for their insightful comments. They also thank anonymous referees for helpful comments. They gratefully acknowledge the generous financial support from the Bank of Korea. The original version of this paper was circulated as a BOK Working Paper with the same title. But the views expressed herein are those of authors and do not necessarily reflect the official view of the Bank of Korea.

** Corresponding Author, Assistant Professor, Department of Economics, Ajou University, Suwonsi, Gyeonggi-do, Korea. Email: tbk@ajou.ac.kr

*** First Author, Assistant Professor, Department of Economics, Dongduk Women’s University, Seoul, Korea. Email: hglee@dongduk.ac.kr
} 


\section{Introduction}

An increasing number of central banks and policy institutions have adopted medium-scale New Keynesian DSGE models and used them as main vehicles of policy analysis. However, as well known among macroeconomists, these models share a critical limitation that they cannot generate unemployment endogenously. Considering that labor market variables such as unemployment rate have been regarded as important indicators of aggregate fluctuations and that they have often been the central issues of the policy debate, the gap between economic reality and theory is too wide to ignore by abstracting away the labor market as standard DSGE models did.

Recently, there have been some progresses in bridging the gap. A number of studies have attempted to overcome this limitation by introducing various labor market frictions into DSGE models to generate endogenous involuntary unemployment. Particularly, two kinds of labor market frictions have been popularly exploited in the related literature. The first one is Mortensen and Pissarides (1994) type search and matching friction, and the other one is a positive wage markup originated from laborer's market power. Trigari (2009) and Galí (2011b) are typical examples incorporating each labor market friction into a standard DSGE model to study labor market dynamics.

Despite the recent academic development, it is hard yet to find any serious attempts to investigate the Korean economy based on a DSGE model with particular attention to the labor market. There are several existing studies on the Korean economy using DSGE models, but they have shared the same limitation that only variations of labor hours are considered with regards to the labor market. However, as discussed above, considering the importance of labor market movements in macroeconomic analysis, it is an unpleasant limitation.

In this regard, at first, this paper proposes a DSGE model with endogenous involuntary unemployment and applies it to the Korean economy. The model is estimated using a Bayesian estimation method; based on estimated model, the joint dynamics of output, inflation and major labor market variables responding to various macroeconomic shocks will be examined. In addition, this paper also studies how the labor market is dynamically adjusted in response to macroeconomic shocks through sectoral reallocation of labor. As the service economy is deepening in Korea as in advanced economies, sectoral labor mobility has received an increasing attention particularly from policy circle. However, there has been only limited literature on the issue, and it has focused mainly on examining secular trends of sectoral employment and their causes. In contrast, this paper will concentrate on analyzing sectoral reallocation of labor in response to various macroeconomic shocks in business cycle frequencies. 
To these ends, a simple DSGE model will be developed with a labor market friction. Its main structure is heavily indebted to Galí (2011b). This approach, unlike other approaches, can generate endogenously involuntary unemployment in the model while preserving the convenience of the representative household framework. However, our model differs from them in two important ways. First, it assumes a small open economy instead of a closed economy to reflect the reality of the Korean economy. Second, multiple sectors are explicitly considered to address the sectoral labor mobility. However, for tractabiliy, only tradable and nontradable goods sectors are assumed. As often in macroeconomic modeling, the tradable and nontradable goods sectors correspond roughly to manufacturing and service sectors respectively.

The main result of this paper can be summarized as follows. First, it is confirmed that the sectoral reallocation of labors plays an important role in the adjustments of Korean labor market responding to some macroeconomic shocks, particularly foreign shocks. Second, the historical decomposition analysis demonstrates that the cyclical fluctuations of unemployment in Korea are mostly explained by key domestic shocks such as domestic productivity shocks and preference shocks. A relatively small contribution of foreign shocks onto aggregate labor market variables is in part due to the sectoral shift of employment rather than changes in aggregate employment and labor force at extensive margins.

The remainder of the paper is organized as follows. Section 2 provides a brief survey of related literature. Section 3 provides a detailed description of the theoretical model. Then, Section 4 explains the choice of the Korean data, the econometric methodology and estimation results. Section 5 concludes with a brief summary of the major findings and a discussion of the limitations of this paper.

\section{Related Literature}

Since Christiano, Eichenbaum, and Evans (2005) and Smets and Wouters (2005), estimated New Keynesian DSGE models have served as a main vehicle of academic and policy analyses. Despite their history of success and popularity, the ignorance of unemployment in these models have been widely recognized as one of their critical shortcomings. Confronting the shortcoming, over the last decade, there have been a lot of attempts in literature to rectify that anomaly by developing frameworks that incorporate labor market imperfections into the New Keynesian model to give rise to unemployment endogenously.

At large, there are two strands in the literature depending on types of labor market friction considered. The first strand of literature emphasizes search and matching friction as a major friction in the labor market. Trigari (2009), Faia (2009), 
Blanchard and Galí (2010) incorporate Mortensen and Pissarides (1994) type search and matching friction into a standard New Keynesian model to explain the joint fluctuations of output, inflation and the labor market and draw implications on optimal monetary policy. Gertler and Trigari (2009) extend Mortensen and Pissarides (1994) by allowing staggered Nash wage bargaining a la Calvo (1983) to generate more realistic volatilities of labor market variables such as unemployment and job vacancies. ${ }^{1}$ In a similar spirit, Gertler, Sala, and Trigari (2008) embed search and matching friction with staggered wage bargaining into a standard New Keynesian framework.

Another strand of literature has been developed more recently. In contrast to models based on search and matching friction, in the literature, unemployment results from a positive average wage markup thanks to the presence of laborers' market power in labor market. Due to positive wage markups, there exists a gap between the prevailing wage and the disutility of work for the marginal laborers, which implies involuntary unemployment for some laborers. Consequently, variations in unemployment over time are associated with changes in wage markups due to exogenous shocks and nominal wage rigidities. Typical examples of this approach can be found in Galí (2011a), Galí (2011b), and Galí, Smets, and Wouters (2011). The first two propose a variant of New Keynesian DSGE models by modifying Erceg, Henderson, and Levin (2000) and, based on it, evaluate implications of nominal wage rigidities on wage inflation and study implications of unemployment to welfare and optimal monetary policy. The last one estimates a similarly constructed model and investigates empirical importance of wage markup shocks in understanding fluctuations of output and employment in the U.S. business cycles. Finally, Rhee and Song (2014) extends the approach for a small open economy and studies its implications on optimal monetary policy and exchange rate.

On the contrary, despite the recent development, it is hard to find any serious analyses of the Korean economy based on a DSGE model with particular attention to the labor market. There have been several attempts to apply New Keynesian DSGE models for the Korean economy. Lee and Yeo (2008), An, Kang, Kim, and Choi (2013), and Kim (2014) are exemplary. Lee and Yeo (2008) applies a small open economy model for the Korean economy to study her business cycle properties and An, Kang, Kim, and Choi (2013) extends a standard New Keynesian small open economy model by introducing financial frictions and estimate it with the Korean macroeconomic data to study the role of financial friction in the Korean business cycle. Kim (2014) also analyzes the Korean economy with a similar small

\footnotetext{
${ }^{1}$ Several studies such as Shimer (2005) point out that a standard search and matching friction model fail in generating realistic volatilities of unemployment and job vacancies responding to shocks of a plausible magnitude.
} 
open economy model but differs from the existing studies in that it considers both stationary shocks and trend shocks at the same time. However, as mentioned above, they share the same limitation of negligence of labor market. In this perspective, this paper aiming to investigate the dynamics of labor market in Korea based on a New Keynesian DSGE model can make meaningful contributions to the existing literature.

This paper is also related with the literature on the sectoral reallocation of labor. As the share of service sector in GDP and total employment is growing in Korea, the sectoral labor mobility, particularly between manufacturing and service sectors, has received an increasing attention especially from policy maker. However, there is only a short list of studies on the issue in literature, and they have focused mainly on examining secular trends of sectoral employments and their causes. To be more specific, Ahn (2009) examines empirically the influences of sectoral differences in productivity and sensitivity to business cycles on the employment dynamics between manufacturing and service sectors. Lee, Park, Park, and Kim (2013) investigates how the degree of inter-industry labor mobility have changed in Korea since 1990s and analyze its determining factors. In contrast, this paper will concentrate on analyzing how the labor market is dynamically adjusted responding to macroeconomic shocks through sectoral reallocation of labors in business cycle frequencies.

\section{Theoretical Model}

In this section, a small open economy model is specified for studying the dynamics of Korean labor market responding to major macroeconomic shocks. The main structure of the model is quite standard in related literature but it has some distinctive features from standard ones, which are worth a brief discussion. First, labor supplies are assumed to be indivisible in that an individual laborer works a fixed number of hours or does not work at all. As a result, decisions on labor market participation are endogenized and all fluctuations of aggregate labor supply take place at extensive margin. Second, it considers explicitly nontradable sectors to address labor adjustments among sectors, particularly tradable and nontradable sectors. Details of the model are described below.

In the theoretical economy, there are three types of goods; final goods and three kinds of intermediate goods. Two kind of intermediate goods are tradable. One kind of intermediate goods are produced and used domestically or exported to foreign markets while the others are imported from abroad by importing firms. The rest of intermediate goods are nontradable. They are produced and used just domestically. A final good is assumed to be nontradable and domestically produced by combining 
all the intermediate goods. In addition, each firm in each intermediate goods sectors is assumed to be a monopolistic competitor and indexed by its product in a continuum of varieties whereas a firm in final good producing sector operates in a perfectly competitive market.

In the following subsection, optimization problems which households and firms face in the economy will be discussed in detail. Before describing them, we will make a brief remark on notation for readers' convenience. All foreign variables have an asterisk $(*)$ to be distinguished from their home equivalent. $H$ or $F$ in subscripts of variables denotes their regional origin. In addition, $s_{t}$ denotes a particular state of the world at time $t$ and the history of events up to time $t$ is represented by $s^{t}=\left(s_{o}, \cdots, s_{t}\right)$. The probability of any particular history of $s^{t}$ is $\pi\left(s^{t}\right)$.

\subsection{Household}

It is assumed that there are a large number of identical households in the theoretical economy and a representative household has a continuum of members. Individual members of the household are characterized by the unit square and indexed by a pair $(i, j) \in[0,1] \times[0,1]$. The first index, $i \in[0,1]$, represents the type of labor service in which a given household member specializes while the second index, $j \in[0,1]$, measures the relative disutility from work compared to other household members supplying the same type of labor service. Preferences over consumption and labor are assumed to be separable. Utility from consumption is given by $\log$ value of the quantities of final goods consumed and augmented with external habit. Disutility from labor supply is given by $\xi\left(s^{t}\right) j^{\gamma}$ where $\xi\left(s^{t}\right)$ is an exogenous preference shifter between consumption and labor. Following Merz (1995) and Galí (2011b), household members are assumed to share their income risks fully among themselves. Along with the assumptions of separability of preferences and symmetricity, it implies that the level of consumption is the same for all household members independently of their job status. Given these assumptions, the household's instantaneous utility is simply given by the integral of its members' instantaneous utilities

$$
\begin{aligned}
U\left(C\left(s^{t}\right)-\right. & \left.h \tilde{C}\left(s^{t-1}\right),\left\{N\left(i, s^{t}\right)\right\} ; \xi\left(s^{t}\right)\right) \\
& \equiv \log \left(C\left(s^{t}\right)-h \tilde{C}\left(s^{t-1}\right)\right)-\xi\left(s^{t}\right) \int_{0}^{1} \int_{0}^{N\left(i, s^{t}\right)} j^{\gamma} d j d i \\
& =\log \left(C\left(s^{t}\right)-h \tilde{C}\left(s^{t-1}\right)\right)-\xi\left(s^{t}\right) \int_{0}^{1} \frac{N\left(i, s^{i}\right)^{1+\gamma}}{1+\gamma} d i,
\end{aligned}
$$

where $\tilde{C}\left(s^{t-1}\right)$ represents the level of aggregate consumption in the previous period 
and $N\left(i, s^{t}\right) \in[0,1]$ is the fraction of members specialized in type $i$ labor service who are employed at the state of $s^{t}$. Before setting up household's optimization problem, additional assumptions are made. As in Erceg, Henderson, and Levin (2000), we assume that labor services are differentiated and monopolistically competitive and that each nominal wage for differentiated labor service is collectively reset with probability of $1-\vartheta_{W}$ via trade union. The remaining part of household's optimization problem is quite standard. Households are assumed to own all the firms in the economy and only uncontingent bonds denominated are allowed for households to share their risks with foreign counterparts.

A representative household determines consumption and new domestic and foreign bond holdings, $C\left(s^{t}\right), B_{H}\left(s^{t}\right)$ and $B_{F}\left(s^{t}\right)$, given bond holdings, $B_{H}\left(s^{t-1}\right)$ and $B_{F}\left(s^{t-1}\right)$, to maximize the sum of discounted expected utilities

$$
\max \sum_{\tau=0} \sum_{s^{t+\tau}} \pi\left(s^{t+\tau}\right) \beta^{\tau} d\left(s^{t+\tau}\right) U\left(C\left(s^{t+\tau}\right)-h \tilde{C}\left(s^{t+\tau-1}\right),\left\{N\left(i, s^{t+\tau}\right)\right\}\right)
$$

subject to sequence of budget constraints

$$
\begin{aligned}
P\left(s^{t+\tau}\right) & C\left(s^{t+\tau}\right)+S\left(s^{t+\tau}\right) B_{F}\left(s^{t+\tau}\right)+B_{H}\left(s^{t+\tau}\right) \\
& \leq \int_{0}^{1} W\left(i, s^{t}\right) N\left(i, s^{t+\tau}\right) d i+\Pi\left(s^{t+\tau}\right) \\
& +S\left(s^{t+\tau}\right) R_{F}^{*}\left(s^{t+\tau-1}\right) B_{F}\left(s^{t+\tau-1}\right)+R_{H}\left(s^{t+\tau-1}\right) B_{H}\left(s^{t+\tau-1}\right),
\end{aligned}
$$

where $\beta$ is the time discount factor and $P\left(s^{t}\right), W\left(i, s^{t}\right)$, and $S\left(s^{t}\right)$ represent overall price index (CPI), wage rate for type $i$ labor service, and nominal exchange rate respectively, and $d\left(s^{t+\tau}\right)$ is an intertemporal preference shock. ${ }^{2}$ $\Pi\left(s^{t}\right)$ represents total dividend from the firms and $R_{H}\left(s^{t}\right)$ and $R_{F}^{*}\left(s^{t}\right)$ denote nominal interest rates applied for domestic and foreign bond at time $t+1$. $^{3}$ The household's utility maximization problem leads to standard first-order conditions and two first-order conditions with respect to bond holdings can be combined to derive the uncovered interest rate parity (hereinafter UIP) condition given as

$$
\sum_{s^{t+1}} \Gamma\left(s^{t}, s^{t+1}\right)\left[R_{H}\left(s^{t}\right) \frac{S\left(s^{t}\right)}{S\left(s^{t+1}\right)}-R_{F}^{*}\left(s^{t}\right)\right]=0,
$$

\footnotetext{
${ }^{2}$ The intertemporal preference shocks have also been known to be one of important sources of business cycle fluctuation according to Justiniano, Primiceri, and Tambalotti (2010).

${ }^{3}$ As Schmitt-Grohé and Uribe (2003) points out, an international business cycle models with incomplete market can have infinite number of steady state equilibria. To close the model with the unique steady state equilibrium, we assume a small cost of bond holdings. For alternative ways of addressing this issue, see Schmitt-Grohé and Uribe (2003).
} 
where $\Gamma\left(s^{t}, s^{t+1}\right) \equiv \beta \frac{d\left(s^{t+1}\right) U_{C}\left(s^{t+1}\right)}{d\left(s^{t}\right) U_{C}\left(s^{t}\right)} \frac{P\left(s^{t}\right)}{P\left(s^{s+1}\right)}$. In addition, when the opportunity to reoptimize wage for $i$ type of labor service arrives, the household members supplying the type of labor services choose their optimal reset wage by solving the maximization problem described above with additional constraint of their labor demand given by

$$
N\left(i, s^{t+\tau}\right)=\left(\frac{W\left(i, s^{t}\right)}{W\left(s^{t+\tau}\right)}\right)^{\frac{1}{\theta_{W}-1}} N\left(s^{t+\tau}\right)
$$

where $\theta_{W}$ is the parameter determining the elasticity of substitution between different types of labor services and $W\left(s^{t}\right)$ and $N\left(s^{t}\right)$ denote the aggregate wage index and employment index which are both derived from firms' optimization problem. ${ }^{4}$ The first-order condition with regard to $W\left(i, s^{t}\right)$ leads to the optimal reset wage as given by

$$
W^{\#}\left(i, s^{t}\right)=-\frac{1}{\theta_{W}} \frac{\sum_{\tau=0} \sum_{s^{t+\tau}} \frac{\pi\left(s^{s+\tau}\right)}{\pi\left(s^{t}\right)}\left(\beta \vartheta_{W}\right)^{\tau}\left[U_{N}\left(s^{t+\tau}\right) W\left(s^{t+\tau}\right)^{\frac{1}{1-\theta_{W}}} N\left(s^{t+\tau}\right)\right]}{\sum_{\tau=0} \sum_{s^{t+\tau}} \frac{\pi\left(s^{t+\tau}\right)}{\pi\left(s^{t}\right)}\left(\beta \vartheta_{W}\right)^{\tau}\left[\frac{U_{C}\left(s^{t+\tau}\right)}{P\left(s^{+t \tau}\right)} W\left(s^{t+\tau}\right)^{\frac{1}{1-\theta_{W}}} N\left(s^{t+\tau}\right)\right]},
$$

where $U_{N}(\cdot)$ and $U_{C}(\cdot)$ are marginal household utilities of labor and consumptions.

Finally, households are assumed to aggregate intermediate goods to produce final goods for consumption. At first, each different kind of intermediate goods are aggregated to produce corresponding composite goods by using the following aggregation technologies:

$$
\begin{aligned}
& Y_{H}\left(s^{t}\right)=\left(\int_{0}^{1} Y_{H}\left(m, s^{t}\right)^{\theta_{T}} d m\right)^{\frac{1}{\theta_{T}}}, \\
& Y_{F}\left(s^{t}\right)=\left(\int_{0}^{1} Y_{F}\left(n, s^{t}\right)^{\theta_{T}} d n\right)^{\frac{1}{\theta_{T}}}, \\
& Y_{N}\left(s^{t}\right)=\left(\int_{0}^{1} Y_{N}\left(l, s^{t}\right)^{\theta_{N}} d l\right)^{\frac{1}{\theta_{N}}},
\end{aligned}
$$

where $Y_{H}\left(s^{t}\right)$ and $Y_{F}\left(s^{t}\right)$ are composite goods produced by aggregating, respectively, domestically produced and imported tradable intermediate goods.

\footnotetext{
${ }^{4}$ Labor demand in future depends on current wage rate due to nominal rigidity. The derivation of wage and employment index will be discussed in detail in firms' maximization problem.
} 
Similarly, $Y_{N}\left(s^{t}\right)$ is composite goods of nontradable intermediate goods. $\theta_{T}$ and $\theta_{N}$ are parameters associated with the elasticity of substitution among each intermediate goods. $m \in[0,1], n \in[0,1]$, and $l \in[0,1]$ are, respectively, indices for each variety of intermediate goods. Final goods are also composite goods which are produced by combining these composite goods based on the following technology given by

$$
Y\left(s^{t}\right)=\left[b Y_{T}\left(s^{t}\right)^{\chi}+(1-b) Y_{N}\left(s^{t}\right)^{\chi}\right]^{\frac{1}{x}},
$$

where $Y\left(s^{t}\right)$ represents final goods while $b$ and $\chi$ are parameters determining relative weights and the elasticity of substitution between tradable and nontradable goods, $Y_{T}\left(s^{t}\right)$ and $Y_{N}\left(s^{t}\right) . Y_{T}\left(s^{t}\right)$ is also composite goods of domestically produced and imported tradable goods given by

$$
Y_{T}\left(s^{t}\right)=\left[a Y_{H}\left(s^{t}\right)^{\rho}+(1-a) Y_{F}\left(s^{t}\right)^{\rho}\right]^{\frac{1}{\rho}}
$$

where $a$ and $\rho$ are parameters determining relative weights and the elasticity of substitution between tradable and nontradable goods. Simple cost minimization problems can be formulated from these aggregations. The solutions of problems lead to standard price indices for composite goods. $P\left(s^{t}\right), P_{T}\left(s^{t}\right), P_{N}\left(s^{t}\right), P_{H}\left(s^{t}\right)$, and $P_{F}\left(s^{t}\right)$ are corresponding price indices for $Y\left(s^{t}\right), Y_{T}\left(s^{t}\right), Y_{N}\left(s^{t}\right), Y_{H}\left(s^{t}\right)$, and $Y_{F}\left(s^{t}\right)$. Demand functions for composite goods, $Y_{T}\left(s^{t}\right), Y_{H}\left(s^{t}\right), Y_{F}\left(s^{t}\right)$, and $Y_{N}\left(s^{t}\right)$, can also be derived from the cost minimization problems. Likewise, demand functions of individual intermediate good, $Y_{H}\left(m, s^{t}\right), Y_{F}\left(n, s^{t}\right)$, and $Y_{N}\left(l, s^{t}\right)$, can be obtained. The explicit formula for price indices and demand functions are omitted to save the space.

\subsection{Firms}

\subsubsection{Domestic tradable intermediate goods producing firm}

Domestic tradable intermediate goods producing sectors produce tradable intermediate goods using a linear technology and labor inputs and sell them at domestic and foreign markets. Each firm in the sectors is assumed to be a monopolistic competitor and faces nominal rigidity as in standard international monetary models. The nominal rigidity is introduced following Calvo (1983) as in the wage settings. For each firm, an opportunity of reoptimizing its price arrives with a probability of $1-\vartheta_{X}$ at each period. A representative domestic intermediate goods producing firm $(\mathrm{m})$ 's profit maximization problem can be formulated as follows. When the opportunity to reoptimize its prices arrives, a representative domestic intermediate goods producing firm chooses its reset prices, $P_{H}\left(m, s^{t}\right)$ and 
$P_{H}^{*}\left(i, s^{t}\right)$, for the home and foreign markets and the inputs of labor, $N_{T}\left(m, s^{t}\right)$, to solve the following profit maximization problem:

$$
\begin{aligned}
\max \sum_{\tau=0}^{\infty} \sum_{s^{t+\tau}} \Gamma\left(s^{t}, s^{t+\tau}\right) \vartheta_{X}^{\tau}\left[P_{H}\left(m, s^{t}\right) Y_{H}\left(m, s^{t+\tau}\right)\right. \\
\left.+S\left(s^{t+\tau}\right) P_{H}^{*}\left(m, s^{t}\right) Y_{H}^{*}\left(m, s^{t+\tau}\right)-W\left(s^{t+\tau}\right) N_{T}\left(m, s^{t+\tau}\right)\right]
\end{aligned}
$$

subject to

$$
\begin{aligned}
Y_{H}\left(m, s^{t+\tau}\right)+Y_{H}^{*}\left(m, s^{t+\tau}\right) & =A\left(s^{t+\tau}\right) A_{T}\left(s^{t+\tau}\right) N_{T}\left(m, s^{t+\tau}\right) \\
Y_{H}\left(m, s^{t+\tau}\right) & =\left(\frac{P_{H}\left(m, s^{t}\right)}{P_{H}\left(s^{t+\tau}\right)}\right)^{\frac{1}{\theta_{T}-1}} Y_{H}\left(s^{t+\tau}\right) \\
Y_{H}^{*}\left(m, s^{t+\tau}\right) & =\left(\frac{P_{H}^{*}\left(m, s^{t}\right)}{P_{H}^{*}\left(s^{t+\tau}\right)}\right)^{\frac{1}{\theta_{T}-1}} Y_{H}^{*}\left(s^{t+\tau}\right),
\end{aligned}
$$

where $A\left(s^{t+\tau}\right)$ and $A_{T}\left(s^{t+\tau}\right)$ represent sector neutral and specific productivity level, respectively, and $\vartheta_{X}$ denotes the probability of not re-optimizing price in the domestic tradable intermediate goods producing sector. $P_{H}^{*}\left(m, s^{t}\right)$ and $Y_{H}^{*}\left(m, s^{t+\tau}\right)$ represent foreign price and demand of domestic tradable intermediate goods. As for the degree of exchange rate pass-through on exports prices, as the optimization problem above suggests, the local currency pricing (LCP) is assumed based on recent empirical evidence.

From the optimization problem, optimal reset prices for the home and foreign markets, $P_{H}^{\#}\left(i, s^{t}\right)$ and $P_{H}^{* \#}\left(i, s^{t}\right)$, are given by

$$
\begin{aligned}
& P_{H}^{\#}\left(m, s^{t}\right)=\frac{1}{\theta_{T}} \frac{\sum_{\tau=0}^{\infty} \sum_{s^{t+\tau}} \Lambda_{X}\left(s^{t+\tau}\right) M C_{T}^{n}\left(m, s^{t+\tau}\right) P_{H}\left(s^{t+\tau}\right)^{\frac{1}{1-\theta_{T}}} Y_{H}\left(s^{t+\tau}\right)}{\sum_{\tau=0}^{\infty} \sum_{s^{t+\tau}} \Lambda_{X}\left(s^{t+\tau}\right) P_{H}\left(s^{t+\tau}\right)^{\frac{1}{1-\theta_{T}}} Y_{H}\left(s^{t+\tau}\right)}, \\
& P_{H}^{* \#}\left(m, s^{t}\right)=\frac{1}{\theta_{T}} \frac{\sum_{\tau=0}^{\infty} \sum_{s^{t+\tau}} \Lambda_{X}\left(s^{t+\tau}\right) M C_{T}^{n}\left(m, s^{t+\tau}\right) P_{H}^{*}\left(s^{t+\tau}\right)^{\frac{1}{1-\theta_{T}}} Y_{H}^{*}\left(s^{t+\tau}\right)}{\sum_{\tau=0}^{\infty} \sum_{s^{t+\tau}} \Lambda_{X}\left(s^{t+\tau}\right) S\left(s^{t+\tau}\right) P_{H}^{*}\left(s^{t+\tau}\right)^{\frac{1}{1-\theta+}} Y_{H}^{*}\left(s^{t+\tau}\right)},
\end{aligned}
$$

where $\Lambda_{X}\left(s^{t+\tau}\right) \equiv\left(\vartheta_{X}\right)^{\tau} \Gamma\left(s^{t}, s^{t+\tau}\right)$ and $M C_{T}^{n}\left(s^{t+\tau}\right)=W\left(s^{t+\tau}\right) /\left(A\left(s^{t+\tau}\right) A_{T}\left(s^{t+\tau}\right)\right)$ is the nominal marginal cost in the domestic tradable intermediate goods producing

\footnotetext{
${ }^{5}$ There is an increasing consensus among recent empirical studies that the degree of exchange rate pass-through on the Korean exports prices has fallen significantly since the Asian financial crisis in 1997 and it can be better described by the local currency pricing.
} 
sector. ${ }^{6} P_{H}^{*}\left(s^{t+\tau}\right)$ is the exports price index of domestic tradable intermediate goods and $Y_{H}^{*}\left(m, s^{t+\tau}\right)$ is the foreign demand of the intermediate goods. Both can be obtained from cost minimization problems derived from the aggregation technology of foreign final demand given by

$$
Y_{H}^{*}\left(s^{t}\right)=\left(\int_{0}^{1} Y_{H}^{*}\left(m, s^{t}\right)^{\theta_{T}} d m\right)^{\frac{1}{\theta_{T}}}
$$

The foreign final demand is parameterized such that it is dependent on its relative price to foreign intermediate goods and the foreign output and simply given as

$$
Y_{H}^{*}\left(s^{t}\right)=\kappa\left(\frac{P_{H}^{*}\left(s^{t}\right)}{P_{F}^{*}\left(s^{t}\right)}\right)^{\omega_{1}}\left(Y^{W}\left(s^{t}\right)\right)^{\omega_{2}},
$$

where $P_{F}^{*}\left(s^{t}\right)$ and $Y^{W}\left(s^{t}\right)$ denote the foreign price of foreign goods denominated in foreign currency and the foreign output while $\omega_{1}$ and $\omega_{2}$ are elasticities of foreign demand to its relative price to foreign intermediate goods and the foreign output.

Finally, labor services are not employed individually in production but employed in a form of composite input of which aggregating technology is given by

$$
N\left(s^{t}\right)=\left(\int_{0}^{1} N\left(i, s^{t}\right)^{\theta_{W}} d i\right)^{\frac{1}{\theta_{W}}}
$$

which implies that $N\left(i, s^{t}\right)$ laborers of type $i$ labor service are required to make $N\left(s^{t}\right)$ units of composite labor input. The demand of each differentiated labor service and wage index are obtained by solving a cost minimization problem formulated from the aggregation technology and they are given as

$$
\begin{aligned}
& N_{T}\left(i, m, s^{t}\right)=\left(\frac{W\left(i, s^{t}\right)}{W\left(s^{t}\right)}\right)^{\frac{1}{\theta_{W}-1}} N_{T}\left(m, s^{t}\right) \text { for } i \in[0,1] \text { and } m \in[0,1], \\
& N_{N}\left(i, l, s^{t}\right)=\left(\frac{W\left(i, s^{t}\right)}{W\left(s^{t}\right)}\right)^{\frac{1}{\theta_{W}-1}} N_{N}\left(l, s^{t}\right) \text { for } i \in[0,1] \text { and } l \in[0,1]
\end{aligned}
$$

\footnotetext{
${ }^{6}$ Note that nominal marginal costs are the same across firms in the sectors due to the same production technology.
} 


$$
W\left(s^{t}\right)=\left(\int_{0}^{1} W\left(i, s^{t}\right)^{\frac{\theta_{W}}{\theta_{W}-1}} d i\right)^{\frac{\theta_{W}-1}{\theta_{W}}}
$$

where $N_{T}\left(m, s^{t}\right)$ and $N_{N}\left(l, s^{t}\right)$ are labor demands in units of employment index while $N_{T}\left(i, m, s^{t}\right)$ and $N_{N}\left(i, l, s^{t}\right)$ are labor demands in the level of individual type of labor services.

\subsubsection{Domestic nontradable intermediate goods producing firm}

Facing a nominal rigidity similarly with a domestic tradable intermediate goods producing firm, with an opportunity to re-optimize its price, a representative nontradable intermediate goods producing firm chooses it price, $P_{N}\left(l, s^{t}\right)$, and the inputs of labor, $N_{N}\left(l, s^{t+\tau}\right)$, to solve the following profit maximization problem:

$$
\max \sum_{\tau=0}^{\infty} \sum_{s^{t+\tau}} \Gamma\left(s^{t}, s^{t+\tau}\right) \vartheta_{N}^{\tau}\left[P_{N}\left(l, s^{t}\right) Y_{N}\left(l, s^{t+\tau}\right)-W\left(s^{t+\tau}\right) N_{N}\left(l, s^{t+\tau}\right)\right]
$$

subject to

$$
\begin{aligned}
& Y_{N}\left(l, s^{t+\tau}\right)=A\left(s^{t+\tau}\right) A_{N}\left(s^{t+\tau}\right) N_{N}\left(l, s^{t+\tau}\right) \\
& Y_{N}\left(l, s^{t+\tau}\right)=\left(\frac{P_{N}\left(l, s^{t}\right)}{P_{N}\left(s^{t+\tau}\right)}\right)^{\frac{1}{\theta_{N}-1}} Y_{N}\left(s^{t+\tau}\right),
\end{aligned}
$$

where $\vartheta_{N}$ denotes the probability of not re-optimizing price in the nontradable intermediate goods producing sector. From the optimization problem, an optimal reset price, $P_{N}^{\#}\left(l, s^{t}\right)$, is given by

$$
P_{H}^{\#}\left(l, s^{t}\right)=\frac{1}{\theta_{N}} \frac{\sum_{\tau=0}^{\infty} \sum_{s^{t+\tau}} \Lambda_{N}\left(s^{t+\tau}\right) M C_{N}^{n}\left(l, s^{t+\tau}\right) P_{N}\left(s^{t+\tau}\right)^{\frac{1}{1-\theta_{N}}} Y_{N}\left(s^{t+\tau}\right)}{\sum_{\tau=0}^{\infty} \sum_{s^{t+\tau}} \Lambda_{N}\left(s^{t+\tau}\right) P_{N}\left(s^{t+\tau}\right)^{\frac{1}{1-\theta_{N}}} Y_{N}\left(s^{t+\tau}\right)},
$$

where $\Lambda_{N}\left(s^{t+\tau}\right) \equiv\left(\vartheta_{N}\right)^{\tau} \Gamma\left(s^{t}, s^{t+\tau}\right)$ and $M C_{N}^{n}\left(l, s^{t+\tau}\right)=W\left(s^{t+\tau}\right) /\left(A\left(s^{t+\tau}\right) A_{N}\left(s^{t+\tau}\right)\right)$.

\subsubsection{Foreign intermediate goods importing firm}

The foreign intermediate goods importing sector also consists of infinite number of firms competing against each other monopolistically. Each firm in the sector imports intermediate goods from abroad, transforms them into differentiated goods, and then supplies them to the final goods producing firms. ${ }^{7}$ In addition, the

\footnotetext{
${ }^{7}$ Note that there is no additional production inputs except for imported foreign intermediate goods
} 
importing firms are also assumed to face nominal rigidity similarly to domestic intermediate good producing firms. Hence, a representative foreign intermediate goods importing firm chooses its price, $P_{F}\left(n, s^{t}\right)$, to maximize the current and future profits

$$
\max \sum_{\tau=0}^{\infty} \sum_{s^{t+\tau}} \Gamma\left(s^{t}, s^{t+\tau}\right) \vartheta_{M}^{\tau}\left[P_{F}\left(n, s^{t}\right) Y_{F}\left(n, s^{t+\tau}\right)-S\left(s^{t+\tau}\right) P_{F}^{*}\left(s^{t+\tau}\right) Y_{F}\left(n, s^{t+\tau}\right)\right]
$$

subject to its demand given as

$$
Y_{F}\left(n, s^{t+\tau}\right)=\left(\frac{P_{F}\left(n, s^{t}\right)}{P_{F}\left(s^{t+\tau}\right)}\right)^{\frac{1}{\theta_{T}-1}} Y_{F}\left(s^{t+\tau}\right)
$$

where $\vartheta_{M}$ is the probability of not re-optimizing its price at each period in the foreign intermediate goods importing sector. The optimization problem leads to the following optimal reset price for the representative foreign intermediate goods importing firm:

$$
P_{F}^{\#}\left(j, s^{t}\right)=\frac{1}{\theta} \frac{\sum_{\tau=0}^{\infty} \sum_{s^{+\tau}} \Lambda_{M}\left(s^{t+\tau}\right) S\left(s^{t+\tau}\right) P_{F}^{*}\left(s^{t+\tau}\right) P_{F}\left(s^{t+\tau}\right)^{\frac{1}{1-\theta}} Y_{F}\left(s^{t+\tau}\right)}{\sum_{\tau=0}^{\infty} \sum_{s^{t+\tau}} \Lambda_{M}\left(s^{t+\tau}\right) P_{F}\left(s^{t+\tau}\right)^{\frac{1}{1-\theta}} Y_{F}\left(s^{t+\tau}\right)},
$$

where $\Lambda_{M}\left(s^{t+\tau}\right) \equiv\left(\vartheta_{M}\right)^{\tau} \Gamma\left(s^{t}, s^{t+\tau}\right)$.

\subsection{Monetary Authority}

The government sector is simplified in that fiscal policy is abstracted away in the model. However, a monetary policy rule should be introduced to close the model. The monetary authority is assumed to set the nominal interest rate according to a simple Taylor-type rule as:

$$
\left(\frac{R_{H}\left(s^{t}\right)}{\overline{R_{H}}}\right)=\left(\frac{R_{H}\left(s^{t-1}\right)}{\overline{R_{H}}}\right)^{\rho_{R_{H}}}\left\{\left(\frac{\Pi_{P}\left(s^{t}\right)}{\overline{\Pi_{P}}}\right)^{\alpha_{c i i}}\left(\frac{Y^{g d p}\left(s^{t}\right)}{\overline{Y^{g d p}}}\right)^{\alpha_{Y}}\right\}^{1-\rho_{R_{H}}} \exp \left(\sigma_{m} \varepsilon_{R}\left(s^{t}\right)\right),
$$

where $\Pi_{P}\left(s^{t}\right)$ and $Y^{g d p}\left(s^{t}\right)$ represents domestic CPI inflation rate and real GDP, respectively, and the variables with bar denote steady state values of original variables. $\rho_{R_{H}}$ is a parameter of interest smoothing, and $\alpha_{c p i}$ and $\alpha_{Y}$

in the transforming process. 
parameters of sensitivity of policy rate to domestic inflation and output gap.

\subsection{Labor Market Statistics}

Since the main focus of this paper is on the dynamics of labor market, it is important to derive labor market statistics properly. This subsection will discuss in detail how to define and derive the labor market statistics in the theoretical model.

Firstly, total and sectoral number of employed can be derived from the labor market clearing condition. The market clearing condition for a labor service $i$ is given by

$$
N\left(i, s^{t}\right)=\int_{0}^{1} N_{T}\left(i, m, s^{t}\right) d m+\int_{0}^{1} N_{N}\left(i, n, s^{t}\right) d n
$$

Two terms in the right hand side of the equation are aggregate demands of labor service $i$ in the tradable and nontradable intermediate goods producing sectors, while $N\left(i, s^{t}\right)$ is number of household members supplying labor service $i$. Rearranging equation (37) using equation (29) and (30) leads to the following relationship

$$
N\left(i, s^{t}\right)=\left(\frac{W\left(i, s^{t}\right)}{W\left(s^{t}\right)}\right)^{\frac{1}{\theta_{W}-1}}\left(N_{T}\left(s^{t}\right)+N_{N}\left(s^{t}\right)\right) .
$$

Total number of employed can be obtained by integrating both sides of the above equation over type of labor services:

$$
E\left(s^{t}\right)=\int_{0}^{1} N\left(i, s^{t}\right) d i=W^{A}\left(s^{t}\right)^{\frac{1}{\theta_{W}-1}} W\left(s^{t}\right)^{\frac{1}{1-\theta_{W}}}\left(N_{N}\left(s^{t}\right)+N_{T}\left(s^{t}\right)\right),
$$

where $W^{A}\left(s^{t}\right)^{\frac{1}{\theta_{W}-1}}=\int_{0}^{1} W\left(i, s^{t}\right)^{\frac{1}{\theta_{W-1}}} d i$. Similarly sectoral numbers of employed in nontradable and tradable sectors are given by

$$
\begin{aligned}
& E_{N}\left(s^{t}\right)=W^{A}\left(s^{t}\right)^{\frac{1}{\theta_{W}-1}} W\left(s^{t}\right)^{\frac{1}{1-\theta_{W}}} N_{N}\left(s^{t}\right), \\
& E_{T}\left(s^{t}\right)=W^{A}\left(s^{t}\right)^{\frac{1}{\theta_{W}-1}} W\left(s^{t}\right)^{\frac{1}{1-\theta_{W}}} N_{T}\left(s^{t}\right) .
\end{aligned}
$$

Labor market participation rate is defined using an incentive compatibility condition derived from the household's utility maximization problem. Individual household members will have an incentive to be employed only if utilities from wages earned from labor services is greater than disutilities arising from supplying 
the labor service. It can be formulated as follows:

$$
\frac{U_{C}\left(s^{t}\right)}{P\left(s^{t}\right)} W\left(i, s^{t}\right) \geq \xi\left(s^{t}\right) j^{\gamma}
$$

Note that the first term in the left hand side, $U_{C}\left(s^{t}\right) / P\left(s^{t}\right)$, is equal to the Lagrangian multiplier in the household's maximization problem. The left hand side of the equation is nominal wage in units of utility, while the opposite side is marginal disutility from labor supply. From the incentive compatibility condition, given $W\left(i, s^{t}\right)$, the labor market participation rate of $i$ type laborers can be defined as:

$$
L\left(i, s^{t}\right)=\left[\frac{1}{\xi\left(s^{t}\right)} \frac{U_{C}\left(s^{t}\right)}{P\left(s^{t}\right)} W\left(i, s^{t}\right)\right]^{\frac{1}{\gamma}},
$$

since the total labor force of $i$ type laborers is normalized as one. The labor force participation rate at aggregate level can be obtained by simply integrating both sides of the equation above over types of labor services.

$$
L\left(s^{t}\right)=\int_{0}^{1} L\left(i, s^{t}\right) d i=\left(\frac{1}{\xi\left(s^{t}\right)} \frac{U_{C}\left(s^{t}\right)}{P\left(s^{t}\right)}\right)^{\frac{1}{\gamma}} W^{L}\left(s^{t}\right)^{\frac{1}{\gamma}},
$$

where $W^{L}\left(s^{t}\right)^{\frac{1}{\gamma}}=\int_{0}^{1} W\left(i, s^{t}\right)^{\frac{1}{\gamma}} d i$. Finally, given the employment rate and labor force participation rate, the unemployment rate $(U E)$ is defined as:

$$
U E\left(s^{t}\right)=1-\frac{E\left(s^{t}\right)}{L\left(s^{t}\right)}
$$

\subsection{Macroeconomic Shocks}

In addition to monetary policy shock discussed before, several macroeconomic shocks are considered in the model as follows. All of the innovations, $\varepsilon$ 's, are white noise with i.i.d processes. Each exogenous state follows an autoregressive process with a given size of innovation, $\exp (\sigma)$ 's. The neutral productivity shock is

$$
\log \left(A\left(s^{t}\right)\right)=\rho_{A} \log \left(A\left(s^{t-1}\right)\right)+\exp \left(\sigma_{A}\right) \varepsilon_{A}\left(s^{t}\right)
$$

The sector specific productivity shocks are, 


$$
\begin{aligned}
& \log \left(A_{T}\left(s^{t}\right)\right)=\rho_{T T} \log \left(A_{T}\left(s^{t-1}\right)\right)+\rho_{N T} \log \left(A_{N}\left(s^{t-1}\right)\right)+\exp \left(\sigma_{A T}\right) \varepsilon_{A_{T}}\left(s^{t}\right) \\
& \log \left(A_{N}\left(s^{t}\right)\right)=\rho_{T N} \log \left(A_{T}\left(s^{t-1}\right)\right)+\rho_{N N} \log \left(A_{N}\left(s^{t-1}\right)\right)+\exp \left(\sigma_{A N}\right) \varepsilon_{A_{N}}\left(s^{t}\right),
\end{aligned}
$$

where each shock process has a spill-over effect to other sector with $\rho_{T N}$ and $\rho_{N T}$. The two preference shocks are the intertemporal shock and the leisure preference shock,

$$
\begin{aligned}
& \log \left(d\left(s^{t}\right)\right)=\rho_{d} \log \left(d\left(s^{t-1}\right)\right)+\exp \left(\sigma_{d}\right) \varepsilon_{d}\left(s^{t}\right) \\
& \log \left(\xi\left(s^{t}\right)\right)=\left(1-\rho_{\xi}\right) \log (\bar{\xi})+\rho_{\xi} \log \left(\xi\left(s^{t-1}\right)\right)+\exp \left(\sigma_{\xi}\right) \varepsilon_{\xi}\left(s^{t}\right) .
\end{aligned}
$$

Lastly, the world GDP shock, world interest rate shock and world price shock are given respectively by the following autoregressive processes

$$
\begin{aligned}
& \log \left(Y^{W}\left(s^{t}\right)\right)=\rho_{Y^{W}} \log \left(Y^{W}\left(s^{t-1}\right)\right)+\exp \left(\sigma_{Y^{W}}\right) \varepsilon_{Y^{W}}\left(s^{t}\right) \\
& 1+R_{F}\left(s^{t}\right)=\left(1-\rho_{R_{F}}\right)\left(1+\overline{R_{F}}\right)+\rho_{R_{F}}\left(1+R_{F}\left(s^{t-1}\right)\right)+\exp \left(\sigma_{m f}\right) \varepsilon_{R_{F}}\left(s^{t}\right) \\
& \log \left(P_{F}^{*}\left(s^{t}\right)\right)=\rho_{P_{F}^{*}} \log \left(P_{F}^{*}\left(s^{t-1}\right)\right)+\exp \left(\sigma_{P_{F}^{*}}\right) \varepsilon_{P_{F}^{*}}\left(s^{t}\right) .
\end{aligned}
$$

\section{Empirical Analysis}

\subsection{Data}

[Table 1] Source of Data

\begin{tabular}{llllll}
\hline Variables & Unit & Type & Freq. & Sample & Source \\
\hline CD rate & $\% / a n n u m$ & NSA & Q & 2000:Q1-2014:Q2 & ECOS 4.1.2 \\
CPI & Index & NSA & Q & 2000:Q1-2014:Q2 & KOSIS \\
Unemployment rate & $\%$ & SA & Q & 2000:Q1-2014:Q2 & KOSIS \\
15yr older Population & Thousands & SA & Q & 2000:Q1-2014:Q2 & KOSIS \\
Employment in Manufac. & Thousands & SA & Q & 2000:Q1-2014:Q2 & KOSIS \\
Employment in Service ${ }^{*}$ & Thousands & SA & Q & 2000:Q1-2014:Q2 & KOSIS \\
Gross Domestic Product & Bil.Won & SA & Q & 2000:Q1-2014:Q2 & ECOS 10.2.1.2 \\
Manufac. Production & Bil.Won & SA & Q & 2000:Q1-2014:Q2 & ECOS 10.2.1.2 \\
Service Production & Bil.Won & SA & Q & 2000:Q1-2014:Q2 & ECOS 10.2.1.2 \\
Total consumption & Bil.Won & SA & Q & 2000:Q1-2014:Q2 & ECOS 10.2.2.2 \\
Total capital formation & Bil.Won & SA & Q & 2000:Q1-2014:Q2 & ECOS 10.2.2.2 \\
Effective Federal Funds Rate & \%/annum & NSA & Q & 2000:Q1-2014:Q2 & FRED \\
Sum of Real GDPs for G20* & Billions & SA & Q & 2000:Q1-2014:Q2 & Global Insight \\
Import Price Index & Index & NSA & Q & 2000:Q1-2014:Q2 & ECOS 7.6.1 \\
\hline
\end{tabular}

Note: ${ }^{\dagger}$ : Constructed based on sectoral employments of KOSIS.

* : Constructed based on sum of G20's real GDPs. 
Data for domestic time series are imported from ECOS (Economic Statistics System of the Bank of Korea) and KOSIS (Korean Statistical Information Service) while data for foreign time series are from FRED and Global Insight. The sample covers from 2000:Q1 to 2014:Q2. CD rate is used as a proxy for the nominal interest rate. Although the interest rate in the model corresponds to the policy interest rate set by the central bank, the interest rate can also be interpreted as the interest rate faced by households. The policy rate for Bank of Korea is the overnight call rate but we chose $\mathrm{CD}$ rate as a proxy for the interest rate for it shows more variations reflecting the state of the economy better than the overnight call rate. CPI is the price index which is converted into inflation rate for the estimation. Unemployment rate is the official rate announced by the Statistics Korea. Data from the Statistics Korea does not have time series that are directly related to employment for tradable and nontradable sectors. Instead, the Statistics Korea announces numbers of employed at industry level such as manufacturing, agriculture, construction, real estate, information and communication, wholesale \& retail, etc. The industries are categorized into two types of sectors, tradable and nontradable. ${ }^{8}$ Then, the numbers of employed in each sector are summed and divided by 15 -yr older population to get the sectoral employment rates.

For output measures, GDP corresponds to the aggregate output while manufacturing production and service production in national product account correspond to tradable and nontradable output, respectively. Note that the consumption variable in the model can be considered as private consumption but also as domestic absorption due to absence of the capital-investment and government consumption in the model. Hence, domestic absorption, a sum of total consumption and total capital formation in data, is used to match with the consumption variable in the model. ${ }^{9}$ The effective federal funds rate of U.S. is the foreign interest rate, the sum of G20s' real GDPs is the world demand and the import price index denominated in foreign currency from ECOS is the world price which is converted to inflation rate for estimation.

All of the time series data are detrended by Hodrick-Prescott filter. The reason why this detrending scheme is used instead of more popular approach with growth rates of variables detrended by a common trend is that macroeconomic times series in Korea within this sample period hardly show common trend which is commonly more observed with developed countries such as U.S. and Europe. For example, the export growth rate of Korea is substantially higher than the GDP growth. Also, the manufacturing sector has been growing relatively more than the service sector in the sample period. Since the model includes quite a few variables of interest that reflect

\footnotetext{
${ }^{8}$ Roughly speaking, the manufacturing sector is the tradable sector while most of service sector is the nontradable. Raw data available upon email request.

${ }^{9}$ We also used the private consumption data instead of domestic absorption but the results do not change qualitatively.
} 
those two sectors, it is hard to guarantee the stationarity of each time series data when detrended by common linear trend. The problem is exacerbated when detrended data with common linear trend are brought to the estimation. A historically retrieved process for the tradable sector specific productivity shows a clear positive trend.

In order to implement Bayesian estimation that requires the Kalman Filter procedure, the stochastic singularity should be addressed properly, in other words, the number of structural shocks should not be less than the number of observables. But since we have twelve observables while nine structural shocks in the model, the measurement errors are necessary. Besides this technical barrier, including measurement errors normally helps the practical estimation with such a highly restricted model like DSGE. The standard deviations of measurement errors for those times series are fixed to $25 \%$ of their own volatilities.

[Table 2] Calibrated Parameters

\begin{tabular}{cccccccccccc}
\hline$\beta$ & $\delta$ & $\omega_{1}$ & $\omega_{2}$ & $a$ & $b$ & $\gamma$ & $\theta_{W}$ & $\theta_{T}$ & $\theta_{N}$ & $\chi$ & $\rho$ \\
\hline 0.9891 & 0.025 & -0.3 & 0.9 & 0.3 & 0.08 & 5 & 0.8368 & 0.875 & 0.8 & -1.27 & $1 / 3$ \\
\hline
\end{tabular}

\subsection{Calibration}

Some parameters in the theoretical model are calibrated rather than estimated because they are widely known as hard to be estimated correctly with macroeconomic time series. Table 2 shows the calibrated parameters and their values. Some parameters are set to standard values following existing literature while some are calibrated to match the Korean data.

The discount factor, $\beta$, has been calibrated to match the inverse of risk free interest rate restricted by the equilibrium condition associated with domestic bond holding. The average interest rate per annum in the sample period was approximately $4.5 \%$ and thus $\beta$ is $\frac{1}{1.045^{25}}$. The depreciation rate is 0.025 which is standard value implying $10 \%$ depreciation for a year. Elasticities of foreign demand to terms of trade and that to foreign output are -0.3 and 0.9 , respectively. For $a$ and $b$, they are calibrated to match the ratios of value-added of nontradable goods sector and exports to GDP respectively with $60 \%$ and $25 \%$ as observed in data.

Elasticities of substitution among differentiated goods or services are normally hard to be identified by aggregate time series data. $\chi$ is -1.27 following Stockman and Tesar (1995) which implies the elasticity of substitution between tradable and non-tradable goods is 0.44. $\rho$ is $1 / 3$ following Chari, Kehoe, and McGrattan (2002) which implies the elasticity of substitution between domestic and imported intermediate goods is 1.5. $\theta_{T}$ and $\theta_{N}$ are 0.875 and 0.8 , respectively. Given these values, the elasticity among differentiated goods in tradable sector is 8 with 
approximately $14.3 \%$ markup rate, while that in the nontradable sector is 5 with $25 \%$ markup rate. This implies that the goods in the tradable sector have slightly higher substitutability relative to those in the nontradable sector. The parameters related to the labor makret are calibrated such that the unemployment rate at the steady state is matched with that in data. From equations (5) and (31), it can be easily shown that the following relationship holds at the steady state

$$
\theta_{W}=\left(\frac{E}{L}\right)^{\gamma}=(1-U E)^{\gamma}
$$

where $E$ and $L$ represent values of total employment and labor force at the steady state. Since the unemployment rate at the steady state is calibrated as $3.5 \%$ as in data, $\gamma$ and $\theta_{W}$ should be calibrated such that they satisfy the equation above together. $\gamma$ is the inverse of Frisch elasticity of labor supply and is usually set as 5 in international macroeconomic models, which implies that the Frisch elasticity of labor supply is equal to 0.2 . With the value of $\gamma, \theta_{W}$ is determined as 0.8368 implying that the elasticity of substitution between differentiated labor services is set to 6.13. Given the elasticity of substitution among labor services, wage markup becomes approximately $19.5 \% .^{10}$

\subsection{Estimation}

Bayesian method is adopted for mapping from data to the model. To make it implementable for estimation and various simulation exercises, the system of stationarized equilibrium conditions is approximated up to first order around the deterministic steady state. ${ }^{11}$ Since the posterior distribution of structural parameters is hard to be characterized analytically, Random Walk Metropolis-Hasting algorithm is used for the numerical approach. The proposal density is Hessian of the likelihood function evaluated at the posterior mode which is estimated via CMAES method. ${ }^{12}$

\subsubsection{Posterior estimates}

The estimation results with parameters of interest are discussed below. The figures show the posterior distributions of parameters. It can be understood that the more smooth posterior distributions demonstrate, the better convergence property

\footnotetext{
${ }^{10}$ Galí (2011b) provides a more detailed explanation on the calibration of parameters determining the inverse Frisch elasticity $(\gamma)$ of labor supply and the elasticity of substitution $\left(\theta_{W}\right)$ among types of labor services in production in a similar model.

${ }^{11}$ For detailed summary of Bayesian estimation with DSGE models, see An and Schorfheide (2007).

${ }^{12}$ This is a class of simulated annealing methods which is better described in Andreasen (2010).
} 
[Table 3] Prior and Posterior Distributions

\begin{tabular}{|c|c|c|c|c|c|c|c|c|}
\hline & \multicolumn{3}{|c|}{ Prior distribution } & \multicolumn{5}{|c|}{ Posterior distribution } \\
\hline & Distr. & Mean & St. Dev. & Mode & Mean & St. Dev. & $5 \%$ & $95 \%$ \\
\hline$h$ & Beta & 0.750 & 0.095 & 0.874 & 0.881 & 0.030 & 0.826 & 0.834 \\
\hline$\vartheta_{x}$ & Beta & 0.500 & 0.151 & 0.968 & 0.929 & 0.020 & 0.898 & 0.902 \\
\hline$\vartheta_{n}$ & Beta & 0.500 & 0.151 & 0.734 & 0.730 & 0.023 & 0.694 & 0.704 \\
\hline$\vartheta_{m}$ & Beta & 0.500 & 0.151 & 0.620 & 0.627 & 0.029 & 0.579 & 0.589 \\
\hline$\vartheta_{w}$ & Beta & 0.500 & 0.151 & 0.005 & 0.006 & 0.001 & 0.004 & 0.005 \\
\hline$\rho_{R}$ & Beta & 0.500 & 0.151 & 0.939 & 0.937 & 0.015 & 0.910 & 0.917 \\
\hline$\gamma_{\pi}$ & Normal & 1.500 & 0.125 & 1.718 & 1.706 & 0.025 & 1.669 & 1.675 \\
\hline$\gamma_{y}$ & Normal & 0.200 & 0.050 & 0.185 & 0.183 & 0.033 & 0.124 & 0.138 \\
\hline$\rho_{A}$ & Beta & 0.500 & 0.151 & 0.152 & 0.151 & 0.053 & 0.070 & 0.084 \\
\hline$\rho_{T T}$ & Beta & 0.500 & 0.151 & 0.731 & 0.723 & 0.028 & 0.683 & 0.689 \\
\hline$\rho_{N T}$ & Beta & 0.231 & 0.154 & 0.065 & 0.041 & 0.025 & 0.005 & 0.008 \\
\hline$\rho_{T N}$ & Beta & 0.231 & 0.154 & 0.439 & 0.434 & 0.023 & 0.389 & 0.399 \\
\hline$\rho_{N N}$ & Beta & 0.500 & 0.151 & 0.577 & 0.636 & 0.050 & 0.565 & 0.574 \\
\hline$\rho_{\xi}$ & Beta & 0.500 & 0.151 & 0.516 & 0.570 & 0.071 & 0.449 & 0.477 \\
\hline$\rho_{Y^{W}}$ & Beta & 0.500 & 0.151 & 0.853 & 0.756 & 0.062 & 0.647 & 0.674 \\
\hline$\rho_{R_{F}}$ & Beta & 0.500 & 0.151 & 0.951 & 0.911 & 0.037 & 0.842 & 0.864 \\
\hline$\rho_{P_{F}^{*}}$ & Beta & 0.500 & 0.151 & 0.455 & 0.192 & 0.086 & 0.350 & 0.380 \\
\hline$\rho_{d}$ & Beta & 0.500 & 0.151 & 0.450 & 0.492 & 0.109 & 0.319 & 0.354 \\
\hline$\sigma_{m}$ & InvGamma & 0.100 & 1.000 & -6.012 & -6.061 & 0.120 & -6.253 & -6.212 \\
\hline$\sigma_{A}$ & InvGamma & 0.100 & 1.000 & -4.267 & -4.047 & 0.110 & -4.223 & -4.186 \\
\hline$\sigma_{A_{T}}$ & InvGamma & 0.100 & 1.000 & -4.100 & -4.089 & 0.117 & -4.280 & -4.240 \\
\hline$\sigma_{A_{N}}$ & InvGamma & 0.100 & 1.000 & -4.057 & -4.130 & 0.119 & -4.321 & -4.281 \\
\hline$\sigma_{\xi}$ & InvGamma & 0.100 & 1.000 & -2.692 & -2.492 & 0.112 & -2.669 & -2.632 \\
\hline$\sigma_{Y^{W}}$ & InvGamma & 0.100 & 1.000 & -4.869 & -5.025 & 0.113 & -5.205 & -5.168 \\
\hline$\sigma_{m f}$ & InvGamma & 0.100 & 1.000 & -5.745 & -6.015 & 0.120 & -6.207 & -6.166 \\
\hline$\sigma_{P_{F}^{*}}$ & InvGamma & 0.100 & 1.000 & -3.259 & -3.310 & 0.104 & -3.479 & -3.443 \\
\hline$\sigma_{d}$ & InvGamma & 0.100 & 1.000 & -2.977 & -3.012 & 0.269 & -3.454 & 3.372 \\
\hline
\end{tabular}

Note: The proposal density is Hessian of the likelihood function evaluated at the posterior mode. The posterior distributions reported above are based on the second half of 2 million draws from MCMC algorithm. The acceptance ratio was approximately $67.16 \%$.

the MCMC chains have. Most of parameters seem to have reasonable convergence considering relatively short sample of Korean data. The table demonstrates both the 
prior distribution and posterior distributions. The prior distributions set for parameters follow standard distributions often used in Bayesian estimation literature. The prior distributions for standard deviations of structural shocks are inverse gamma distributions. ${ }^{13}$ Priors for parameters that range between zero and one are beta distributions with fairly loose standard deviations. Those include the persistence parameters for structural shocks, technology spillover parameters, Calvo parameters, interest rate smoothing parameter and habit persistence. With the exception of technology spillover parameters and habit persistence, the means of priors are 0.5. Based on previous studies, it is well accepted that the habit persistence show quite a high degree and thus the mean for the prior is set at 0.75 . On the other hand, the technology spillover parameters are set relatively lower value than 0.5 , otherwise the MCMC chain may stay in the region in which the invertibility condition of the Jordan form of the equilibrium system is violated. ${ }^{14}$ With sensitivity parameters of Taylor rule, the priors are set rather tightly. Without a tight prior on the sensitivity parameter of the inflation gap, it is generally difficult to maintain the determinancy region of the system.

As common with estimated DSGE models, the posterior estimates for the persistence parameters of structural shock processes mostly show quite a high degree. The exception is the persistence for the total factor productivity shock, $\rho_{A}$, which is estimated to be relatively mild. But it is not too surprising since the model specifies two different productivity processes for each sector. The technology spillover parameters also show some contrasting estimates. Both posterior means and modes indicate the spillover from the tradable sector to the nontradable sector is considerably stronger than that of the opposite direction. This indicates an open economy like Korea who faces the competitive global market via trading experiences the technology spillover relatively more from the tradable sector than the nontradable sector.

The Calvo parameters estimates show some disparate results depending on sectors. The Calvo parameter for the tradable, nontradable and importing sectors show high degree while that in wage setting is much lower. The finding on the low degrees of price and wage frictions is consistent with other works on Korean data estimation of DSGE models. On the other hand, the different degrees of Calvo parameters for tradable and nontradable sectors seem to be somewhat counterintuitive. We would expect that the price friction for tradable sector would be lower than that for nontradable since the tradable sector faces more competitive market but the results show otherwise. However, estimates for Calvo parameters are often

\footnotetext{
${ }^{13}$ The standard deviations are converted by natural logarithm and thus mostly show negative signs indicating values approximately less than 2 .

${ }^{14}$ It can be deduced from the experiments of drawing impulse response function with high degree of spill-over parameters. Most of impulse responses of variables will not converge back to the steady state within any reasonable time horizon.
} 
sensitive with the degree of elasticities of substitution between differentiated goods or labor services and thus in general difficult to be identified with available macro time series data. This issue was also mentioned by Iskrev (2010).

[Figure 1] Posterior Distributions

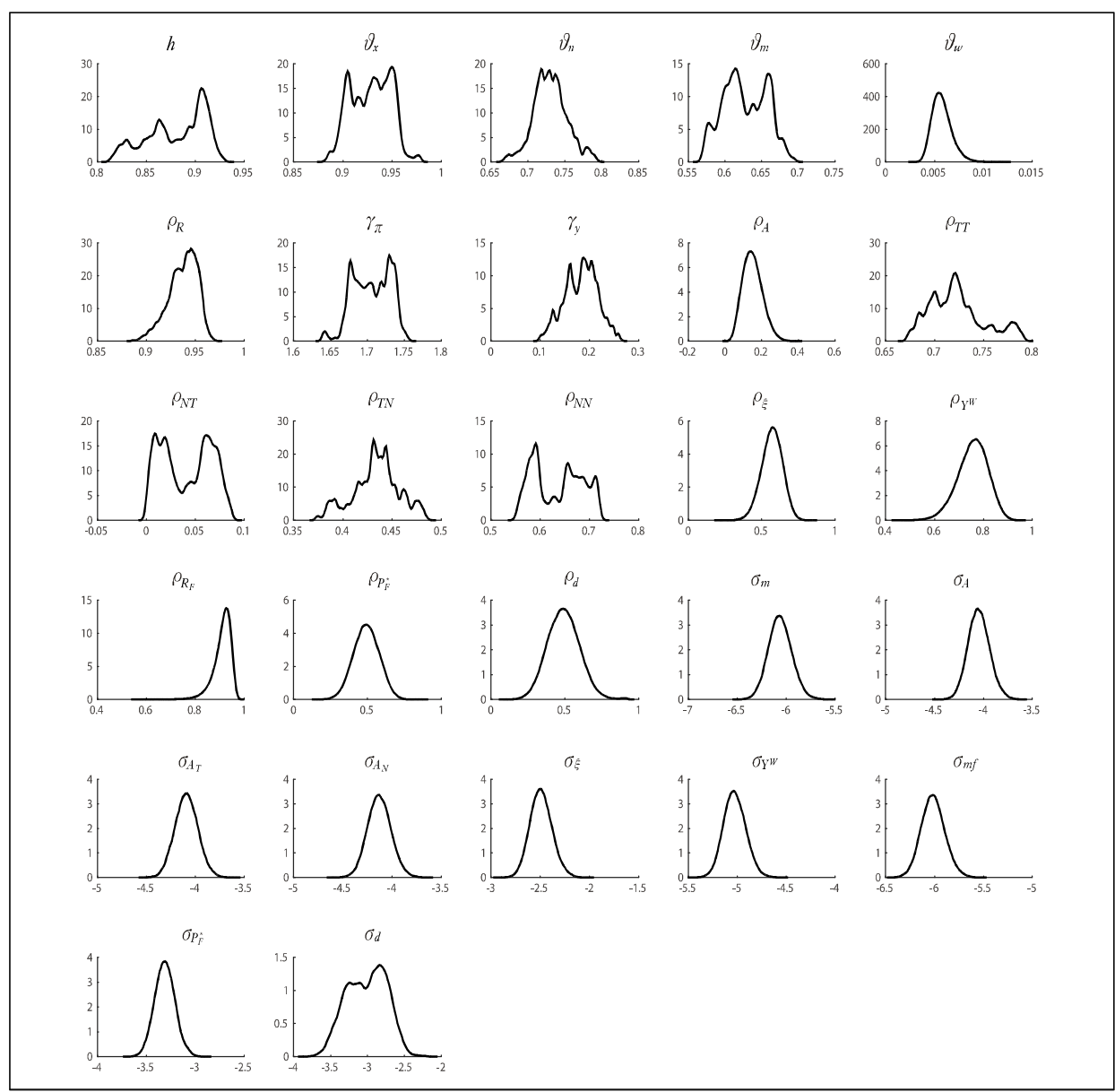

\subsubsection{Impulse response function analysis}

This section illustrates the impulse response functions for variables of interest given unexpected change in the structural shocks. All of the shocks' sizes are oneunit increases of estimated standard deviations of their own. In the figures, the output and sectoral employment response functions are percentage deviations, i.e., the natural logarithm deviations, from the steady state while others are the responses in levels. Inflation rates and interest rates are annualized. In the output subplot of each figure, the blue dotted line is the domestic absorption while the red line is the GDP. The employment rates and unemployment rates are all converging 
back to the their steady-state levels which are calibrated to match with Korean employment data. For example, the unemployment rate of Korea during the sample period is approximately $3.5 \%$ while the total employment rate $59.3 \%$.

[Figure 2] IRFs to Sector Neutral Productivity Shock

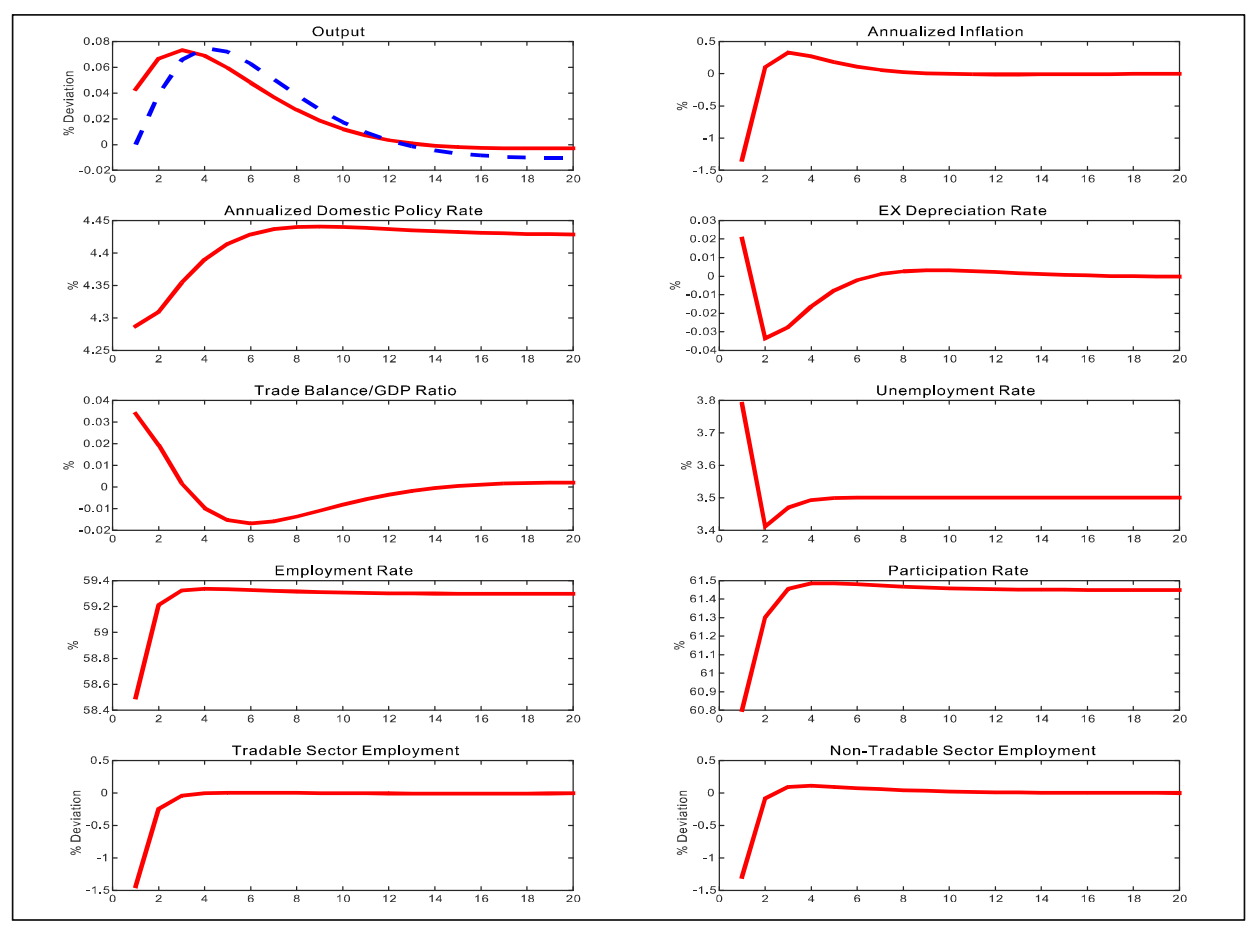

Note: Solid line and dashed line in the top left panel denote output and domestic absorption, respectively. Output and sectoral employment rates are \% deviations from the steady-state while others are the responses in levels.

The impulse response functions to a sector neutral productivity shock presented in Figure 2 are consistent with findings in conventional macroeconomic models. Both output and domestic absorption respond to the shock positively with humpshaped fashion and inflation declines on impact. Output reaches at maximum, approximately $0.07 \%$, after three quarters while domestic absorption does after four quarters. Due to the decline of inflation which is dominating rise in output, the interest rate following the monetary policy rule falls. ${ }^{15}$ With this decline of the domestic interest rate, the UIP condition induces the rise in the exchange depreciation rate which is accompanied by trade balance surplus. The decline of the total employment rate might reflect the contractionary effects of a productivity

\footnotetext{
15 The fall of policy rate in response to a productivity shock reflects the estimated monetary policy rule with a higher weight on inflation gap. However, as discussed in Choi and Wen (2010), it may not be optimal for monetary authority to response to inflation movements induced by supply-side shocks.
} 
[Figure 3] IRFs to Tradable Sector Productivity Shock

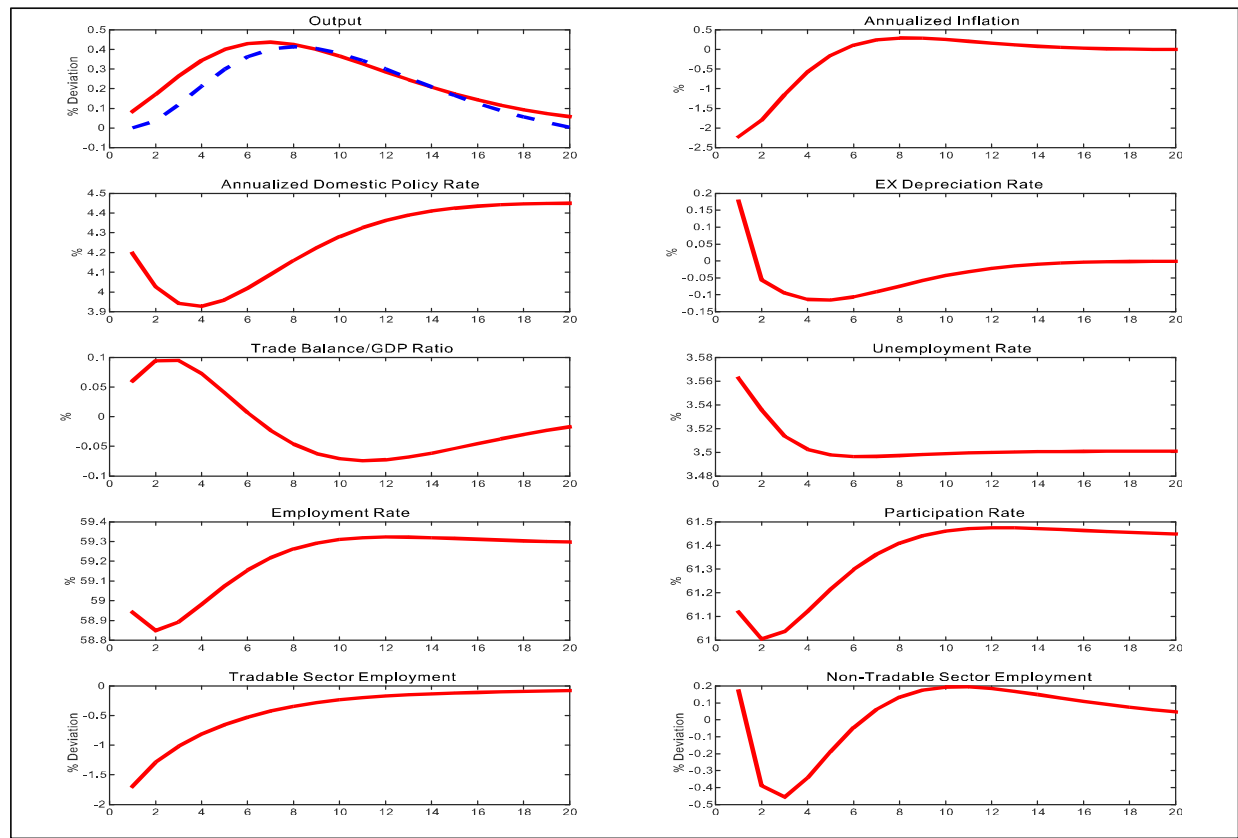

Note: Solid line and dashed line in the top left panel denote output and domestic absorption, respectively. Output and sectoral employment rates are \% deviations from the steady-state while others are the responses in levels.

[Figure 4] IRFs to nontradable Sector Productivity Shock

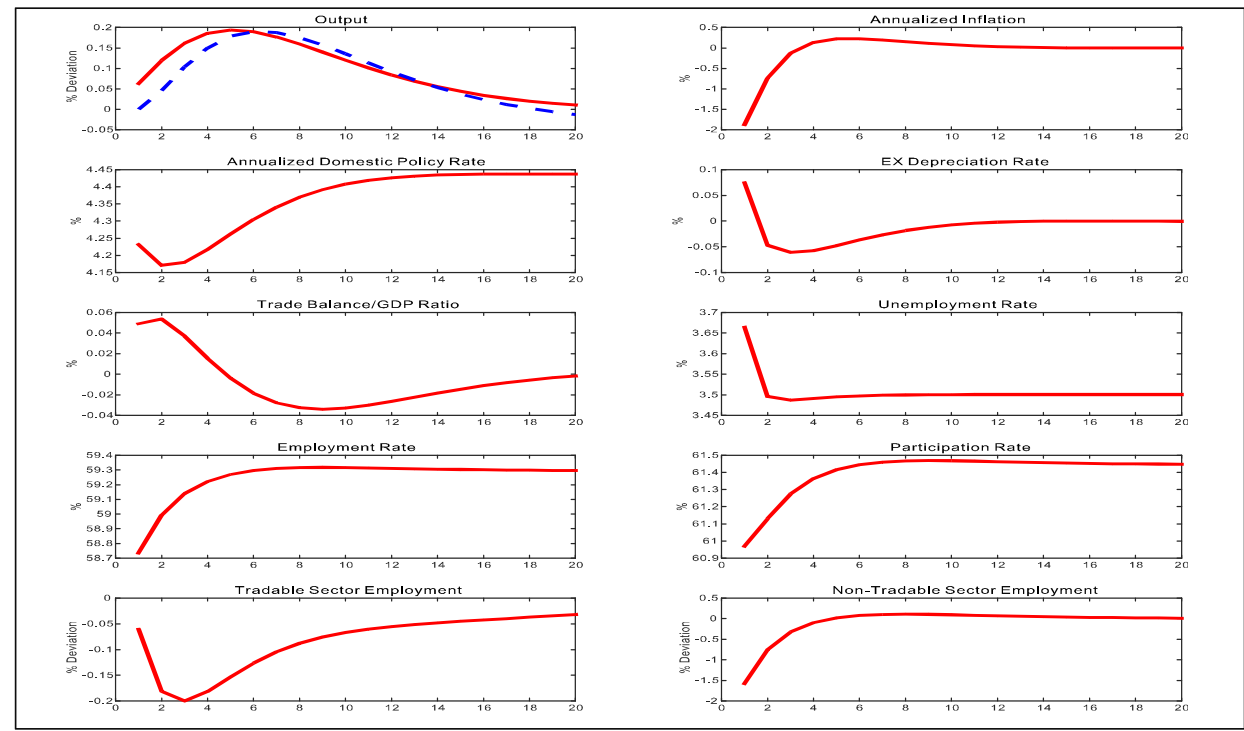

Note: Solid line and dashed line in the top left panel denote output and domestic absorption, respectively. Output and sectoral employment rates are \% deviations from the steady-state while others are the responses in levels. 
shock on labor demand, which is often found in the class of New Keynesian models. On the other hand, in general, the positive wealth effect from the productivity improvement reduces the incentive for labor supply while the substitution effect of real wage increase increases the labor supply. Hence, the fall of participation rate reveals the dominance of wealth effect. Overall, the unemployment rate rises which implies that determination of unemployment rate is more driven by the labor demand force. Sectoral responses in employments are analogous to the aggregate employment responses.

Figure 3 and 4 show the responses to productivity shocks in tradable and nontradable sectors. Overall dynamics of aggregate variables are similar to the impulse response functions to the sector neutral productivity shocks. Both sectoral productivity shocks induce the total employment to decrease and the unemployment to increase. This implies that determination of aggregate labor variables such as unemployment rate and employment rate in response to sectoral productivity shocks is more driven by the labor demand factors as for sector neutral productivity shock. Sectoral employment responses are dependent on the origin of sectoral productivity improvements. Sectoral employment directly benefited from their own sectoral productivity shocks apparently shrink. On the contrary, the overall dynamics of employment in the other sector is ambiguous. It is subject to variations depending on parameter estimates.

[Figure 5] IRFs to Domestic Monetary Shock

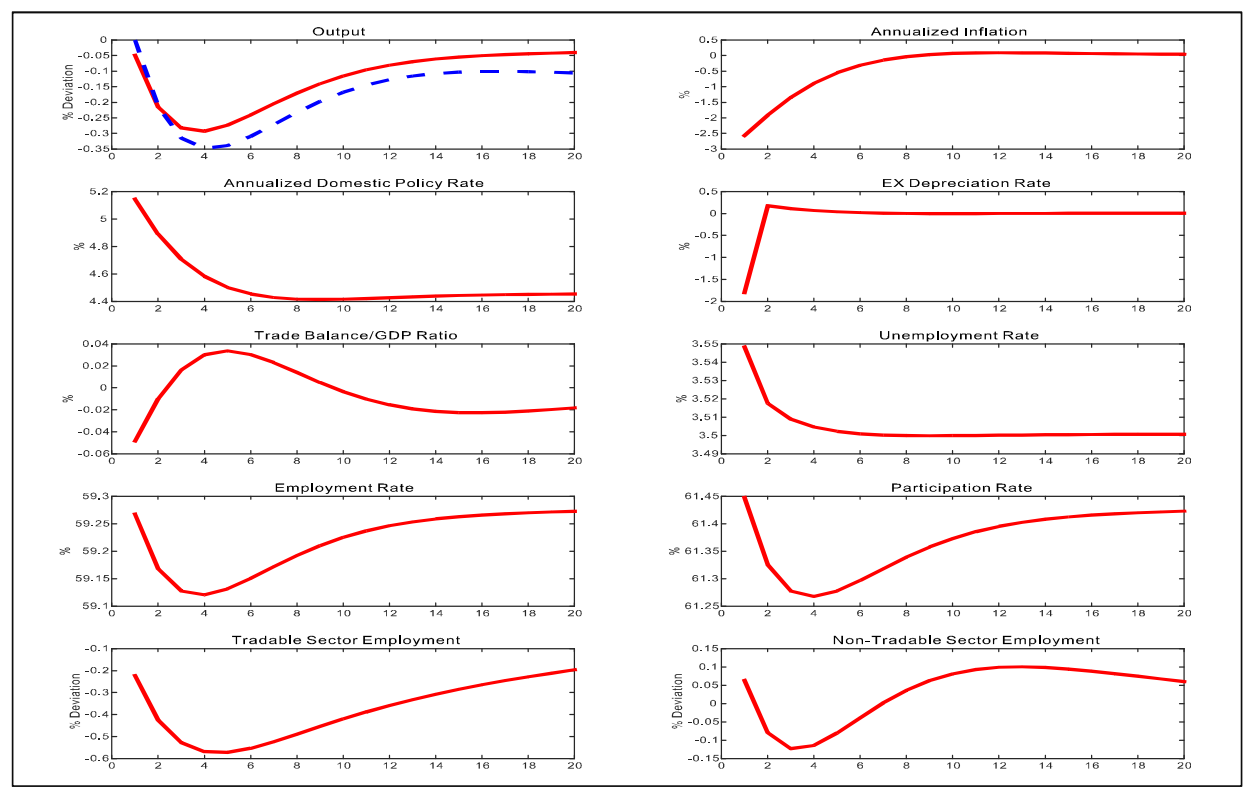

Note: Solid line and dashed line in the top left panel denote output and domestic absorption, respectively. Output and sectoral employment rates are \% deviations from the steady-state while others are the responses in levels. 
Figure 5 shows the reactions in response to the one-unit standard deviation of the monetary policy shock. This increases approximately 70 basis point of the domestic interest rate on impact. Output and inflation decline due to a contractionary monetary policy. The monetary policy shock also bring contraction to the labor market as well. The employment rate falls and unemployment rises. This implies the employment decreases further than the participation decrease. And sectoral responses are following those of the aggregate labor market variables and show no significant heterogeneity. The trade balance deteriorates due to the appreciation of domestic currency to satisfy the UIP condition entailed by the interest rates differentials.

Figure 6 is the responses of the leisure preference shock which can also be interpreted as a labor supply shock. Due to a sudden contraction of labor supply, the overall output declines and the inflation rate rises. A positive shock on the leisure preference decreases the employment rate along with sectoral employments and the participation rate. However, the unemployment rate declines indicating that the fall in employment is muted by a stronger decline in the participation. The domestic interest rate rises reflecting the inflation rise. Accordingly, the domestic currency appreciates and trade balance deficit occurs since the gap between domestic and foreign interest rates has widened.

[Figure 6] IRFs to Leisure Preference Shock

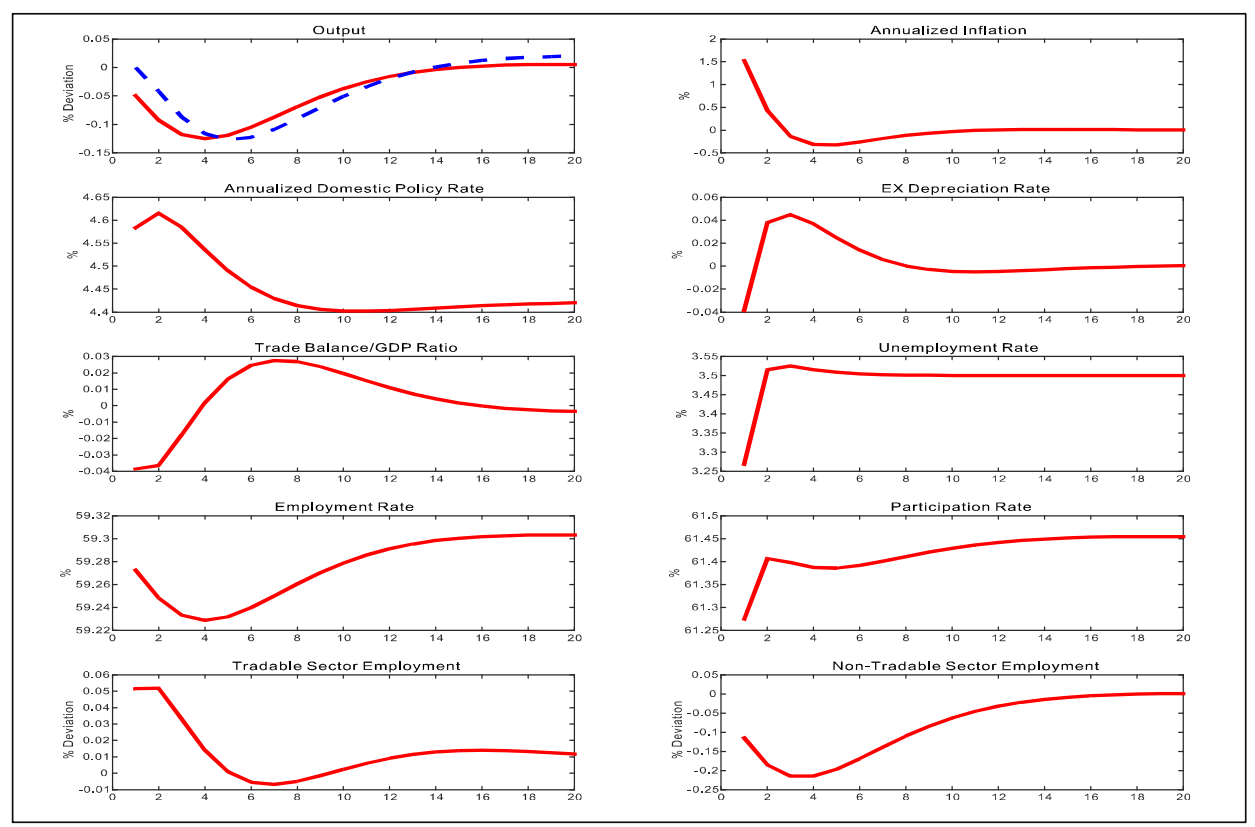

Note: Solid line and dashed line in the top left panel denote output and domestic absorption, respectively. Output and sectoral employment rates are \% deviations from the steady-state while others are the responses in levels. 
[Figure 7] IRFs to World GDP Shock

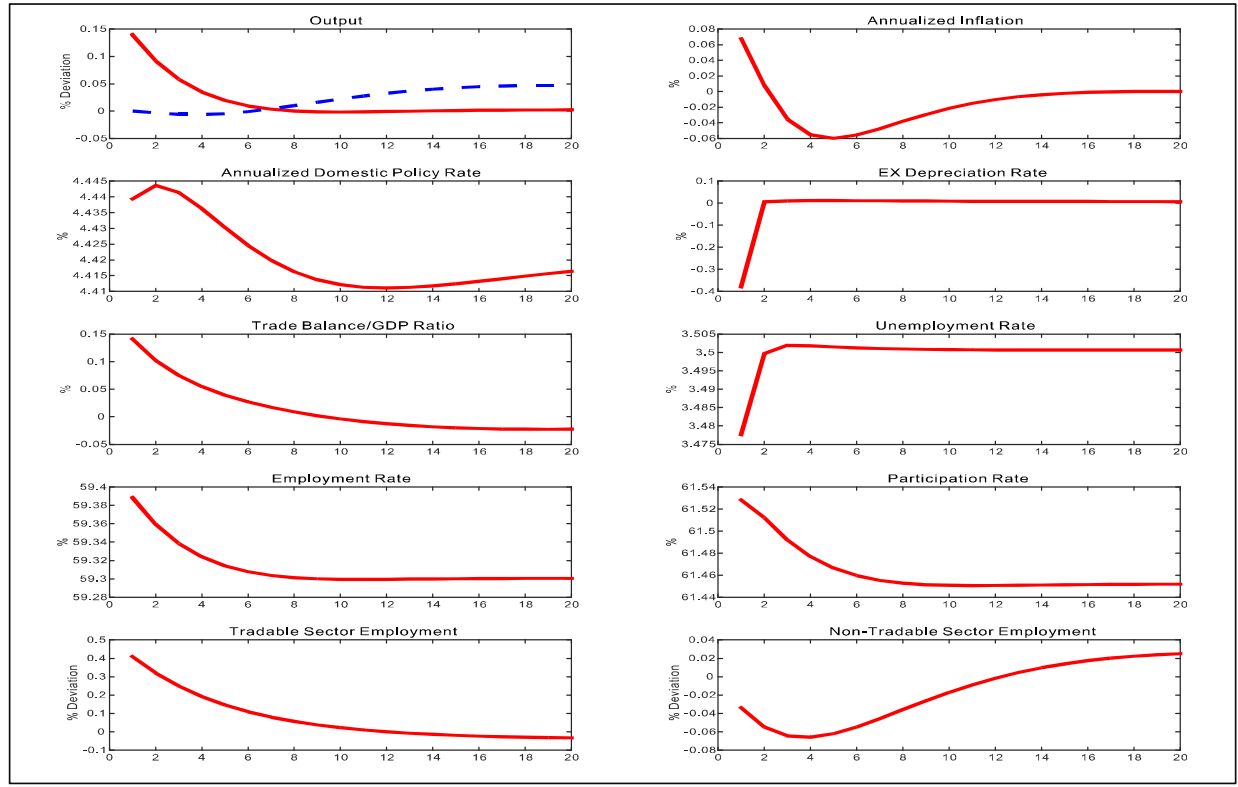

Note: Solid line and dashed line in the top left panel denote output and domestic absorption, respectively. Output and sectoral employment rates are \% deviations from the steady-state while others are the responses in levels.

[Figure 8] IRFs to Foreign Interest Rate Shock

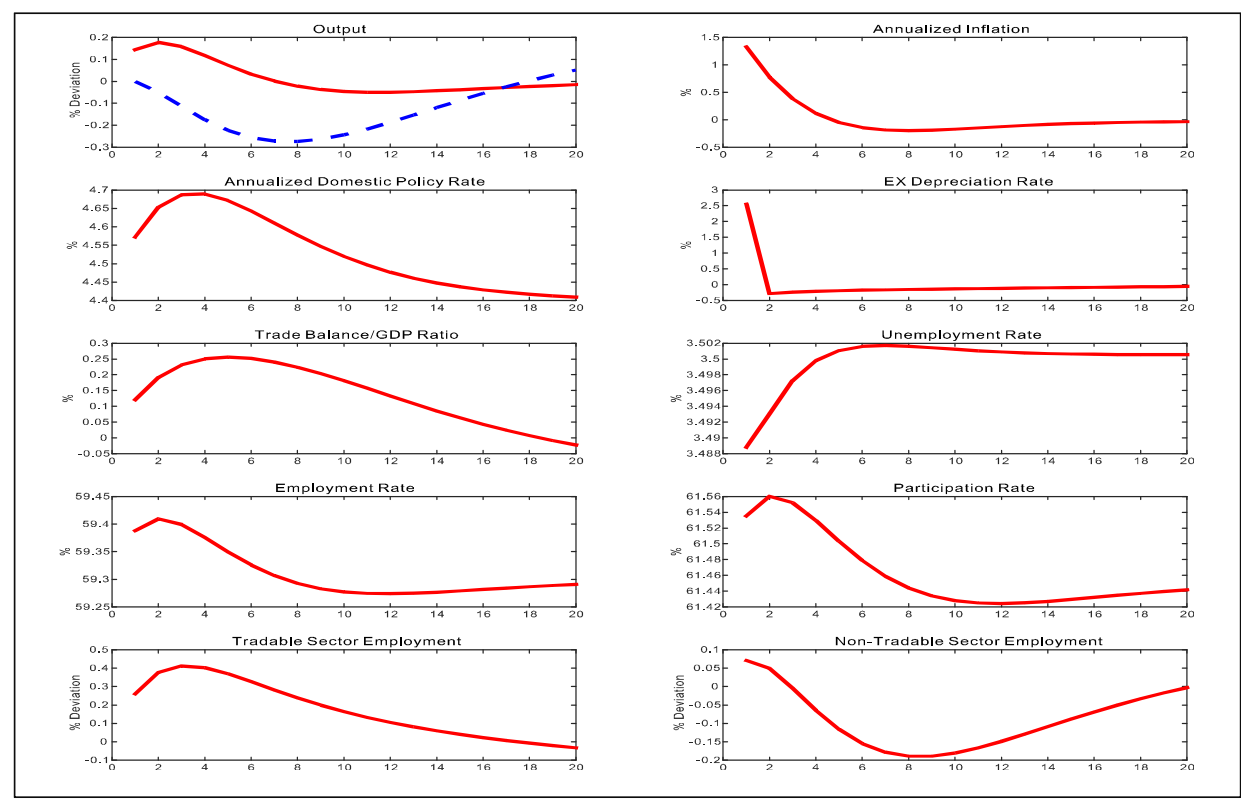

Note: Solid line and dashed line in the top left panel denote output and domestic absorption, respectively. Output and sectoral employment rates are \% deviations from the steady-state while others are the responses in levels. 
Figure 7 shows the impulse response functions to a foreign demand shock as defined by a positive world GDP shock. As predicted by most of the open macroeconomic models, an increase in foreign demand causes both output and inflation to increase. However, the domestic absorption rises with some delay, which might be attributed partially to consumption smoothing. At the same time, the domestic interest rate rises and the UIP condition will drive the exchange rate to appreciate. However, a trade balance surplus occurs initially to a large extent but monotonously decreases as the effect of nominal exchange rate becomes unfolded. Most distinctive observation in this figure is that sectoral numbers of employment behave disparately responding to the foreign demand shock. The employment in tradable sectors increase approximately by $0.4 \%$ on impact due to increase in exports demand while the employment in nontradable sectors decrease approximately by $0.04 \%$ on impact. This result suggests that a sectoral shift of labor takes place to accommodate the foreign demand shock in Korea. ${ }^{16}$ In contrast to sectoral employment, the magnitudes of aggregate changes of labor market variables are small compared to those of impulse responses to other shocks, which implicates that changes in sectoral employment mostly come from sectoral shift of employment rather than changes in aggregate employment and labor force at extensive margins.

The impulse response functions to the foreign interest rate shock is shown in Figure 8. According to standard international macroeconomic theories, a foreign interest rate shock can be absorbed by adjustments of both domestic interest rate and nominal exchange rate under flexible exchange rate regime. Consistent with these theories, after a hike in foreign interest rate, the exchange rate depreciates rapidly on impact while at the same time the domestic interest rate rises with humpshaped fashion. Output increases due to an expansion of foreign demand by a sharp depreciation, but domestic absorption gradually falls thanks to intertemporal substitution induced by nominal interest rate increase. Contrasting responses of output and domestic absorption result in a large trade surplus. This external adjustment after the shock is also embedded in dynamics of sectoral employment. Once again sectoral mobility of labor plays a crucial role in accommodating the foreign shock. Reflecting increase in foreign demand, the employment in tradable sectors increase, while that in nontradable sectors decrease due to temporary contraction of domestic demand. The reason is that the foreign interest rate shock works analogously for the labor market via expansion of foreign demand induced by adjustment of exchange rate.

\footnotetext{
${ }^{16}$ As an anonymous referee points out legitimately, the sectoral reallocation of labors reported in this paper may simply reflect the structure of theoretical model, not that of data. To address this concern, we estimate a simple SVAR model consisting of a foreign shock variable, GDP and sectoral employments. The estimated Impulse response functions from the SVAR model display similar dynamics as presented in this paper. These results can be considered as another evidence of existence of sectoral reallocation of labors in Korea. The details of SVAR model will be available on request.
} 
[Figure 9] IRFs to Foreign Price Shock

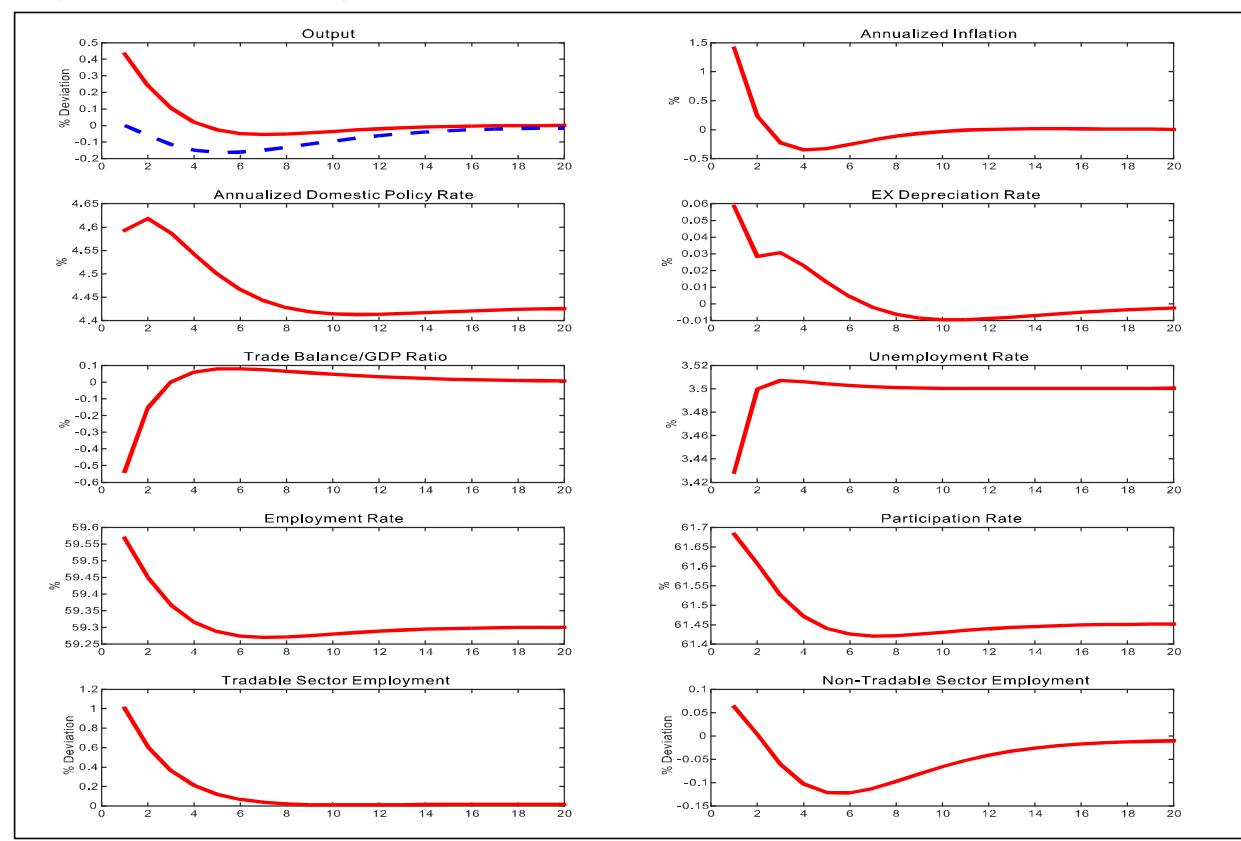

Note: Solid line and dashed line in the top left panel denote output and domestic absorption, respectively. Output and sectoral employment rates are \% deviations from the steady-state while others are the responses in levels.

Lastly, Figure 9 shows the impulse response functions to a positive foreign price shock. Overall responses to the foreign price shock are within expectation of standard macroeconomic theories. However, the output expansion is unrealistically too strong after a positive foreign price shock, which contradicts the general notion on the Korean economy. This particular result might indicate that the elasticity of exports to nominal exchange rate in the model is estimated to be too high. Meanwhile, the impulse response functions of both aggregate and sectoral variables in the labor market show qualitatively same dynamics to those in other foreign originated shocks.

\subsubsection{Historical decomposition}

Figure 10 shows all of the historical movements of the structural shocks. Most conspicuous movements can be observed around 2008 when the global financial crisis has emerged. It is clear that the crisis is captured by the sharp decline in the world GDP shock along with the foreign interest rate and foreign price shocks followed by the domestic monetary policy shock. Moreover, a considerable magnitude of decline can be observed with the intertemporal preference shock as well at the beginning of 2009. However, we do not interpret that this shock's movement is generated solely from the domestic conditions. In the model, the 
intertemporal preference shock serves as a wedge not only between the price of domestic bond and the stochastic discount factor, but also between the price of domestic bond and that of foreign bond. In other words, the intertemporal preference shock can be thought as the risk premium in both domestic and international financial markets. ${ }^{17}$ Hence, it is not surprising to see the large swings of the intertemporal preference shock during the global financial crisis which is likely reflecting the financial distress in both domestic and international markets. ${ }^{18}$ The foreign price shock's movement mostly coincide with the well known episodes of big swings in commodity prices. Evidently, the sharp rise before the financial crisis is reflecting the oil price peak. Besides the financial crisis, the two preference shocks also show significant drops in mid-2000s which reflect the credit card crisis of Korea.

[Figure 10] Historical Structural Shocks

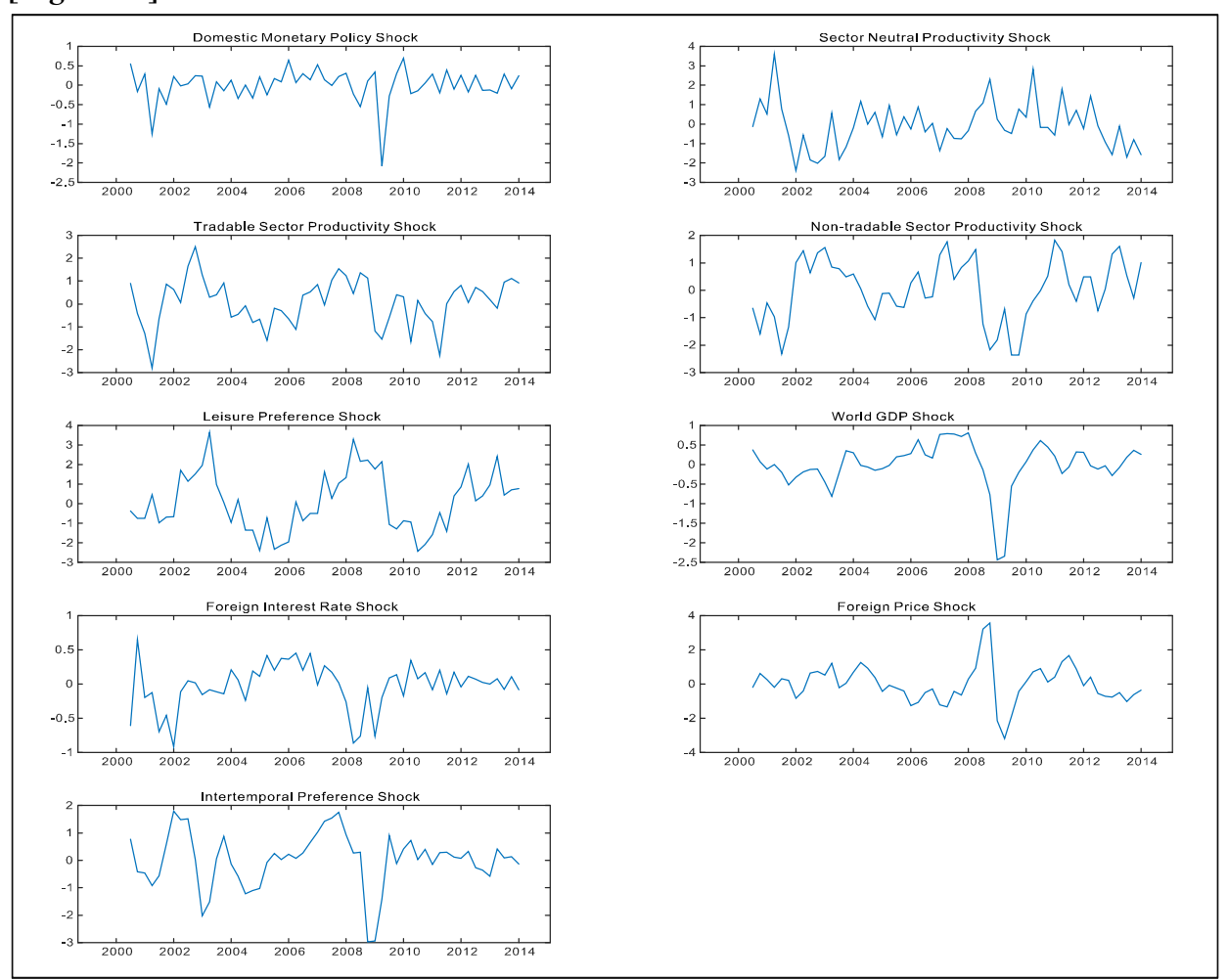

Note: Given the posterior estimates of parameters, the historical shocks have been retrieved by the backward smoothing Kalman Filter.

${ }^{17}$ The intertemporal preference shock in our model is in some sense a reduced form shock of a domestic financial friction such as Christiano, Trabandt, and Walentin (2011) and the country risk premium such as Neumeyer and Perri (2005).

${ }^{18}$ Consistent with our results, Uribe and Yue (2006) also argues the country risk premium is the main driving force of business cycle fluctuations in emerging markets. 
[Figure 11] GDP Historical Decomposition

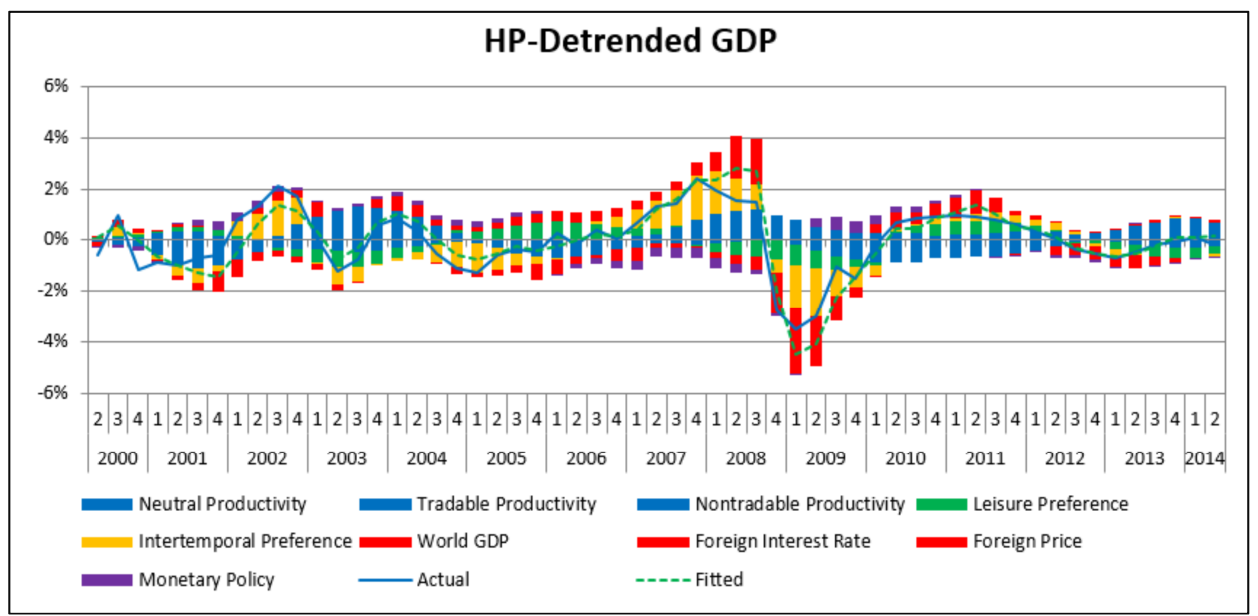

Note: Solid line and dashed line denote the observed time series and fitted values, respectively.

To see the contributions of these historical shock upon the macro variables of interest, Figure 11, 12 and 13 show the historical decompositions of GDP, inflation rate and unemployment rate. The solid line represents the actual observation of time series while the dotted line represents the fitted variables by the estimated model. The gap between those two lines can be interpreted as the measurement error. Those lines demonstrate the model's fit to the actual observations is fairly acceptable. For each quarter of the observed variables, each bar with colors correspond to the contribution of one of the structural shocks as indicated by the legends. The bars above the zero line represent the positive contribution of relevant shocks whereas the bars below the zero represent the negative contribution of the shocks to the variable. Hence, the sum of those bars within each quarter should be same as the dotted line. All of the variables are HP-detrended and the figures show only the cyclical movements.

As can be expected from the conventional business cycle literatures, three productivity shocks seem to be the important driving forces of overall fluctuations of GDP. However, the intertemporal preference shock and three foreign shocks also have significant contributions to GDP at some episodes. More specifically, the contraction in 2003-2004 is generally perceived as the financial distress of households from credit card crisis and this is mostly reflected by the intertemporal preference shock's contribution to GDP. Meanwhile, during financial crisis in 2008, the foreign shocks together with the intertemporal preference shock are mainly contributing to the sharp decline of GDP. Evidently, those crisis episodes that showed turmoils in the financial market are both captured by the intertemporal preference shock. It is worth to note that the expansionary monetary policy shock in 2009 has some positive effects on GDP. 
[Figure 12] Inflation Rate Historical Decomposition

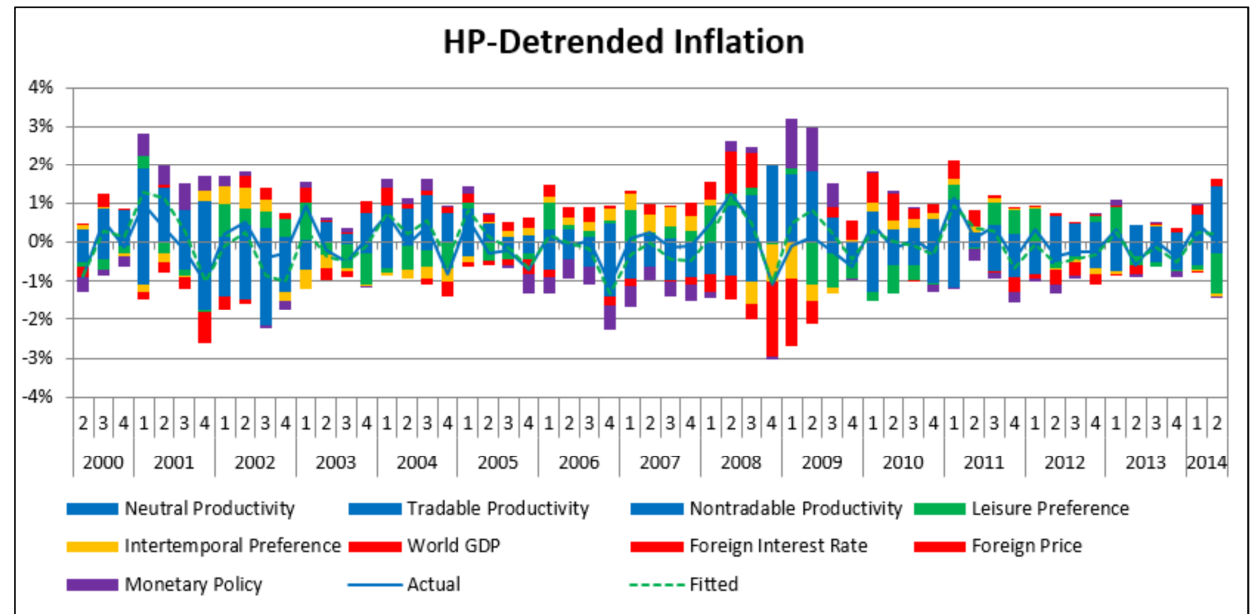

Note: Solid line and dashed line denote the observed time series and fitted values, respectively.

[Figure 13] Unemployment Rate Historical Decomposition

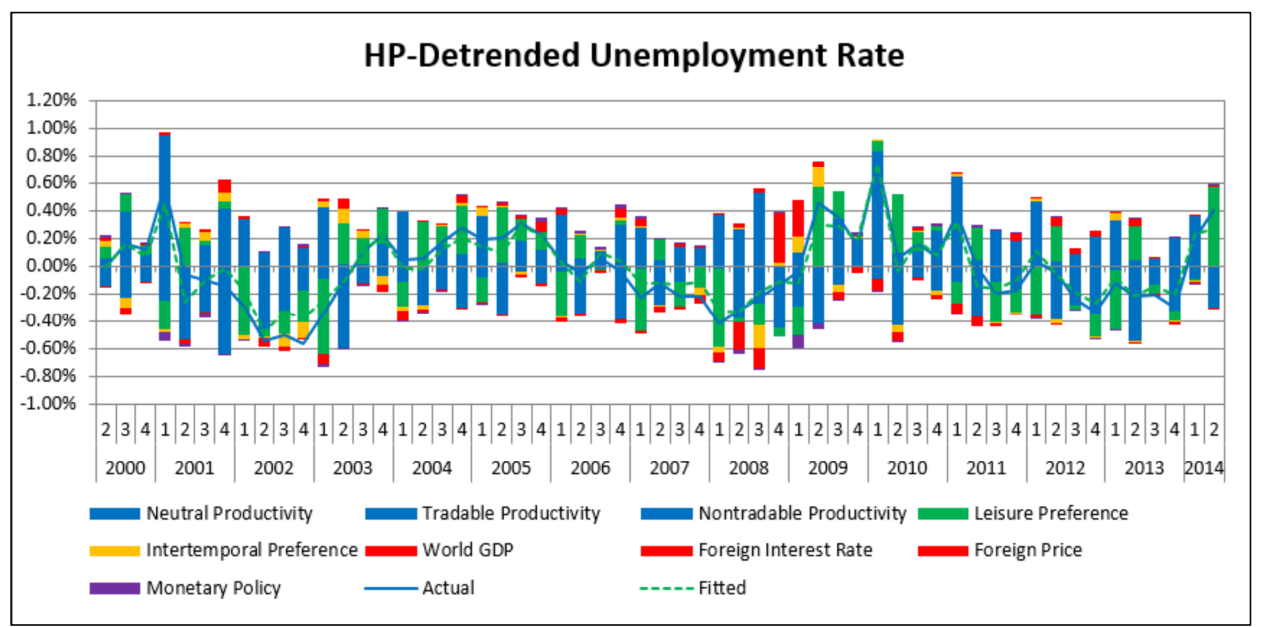

Note: Solid line and dashed line denote the observed time series and fitted values, respectively.

The inflation rate is strongly influenced by the preference shocks and productivity shocks implying that both aggregate demand and supply forces are the major source of fluctuations. Foreign price shocks seem to affect the inflation before the global financial crisis while their contributions to the inflation dramatically fall after the crisis. ${ }^{19}$ The historical decomposition of inflation rate shows the monetary policy stance more clearly than that of GDP. The monetary policy was mostly

\footnotetext{
${ }^{19}$ Although foreign price shock's contribution is not distinguishable from other foreign shocks in the figure, detailed figures on its contribution can be provided upon request.
} 
contractionary in the mid-2000s but turned to be quite inflationary to dampen the adverse effects of the crisis around 2009. But more recently, the contributions of foreign shocks and monetary policy shock to inflation seem to stay moderately low.

The historical decomposition of unemployment rate shows that the domestic shocks contribute more strongly to unemployment rate than to the inflation rate or GDP as it was confirmed from the impulse response functions analysis. The productivity shocks and leisure preference shock are the dominant factors generating the fluctuations of the unemployment rate, although the contribution of productivity shocks are less persistent. As for the global financial crisis periods, the overall unemployment rate has not responded to the crisis until 2009 when the positive productivity shocks were driving unemployment rate to escalate. Also, it is worth to note that the foreign price shock's contribution onto unemployment seems exceptionally large around 2008. The positive foreign price shock in second and third quarter of 2008 has influenced reducing the unemployment, while the negative foreign price shock has increased the unemployment in last quarter of 2008 and first quarter of 2009.

In order to quantify the overall contributions of each structural shocks to the variations of GDP, inflation rate and unemployment rate in the sample period, the percentage contributions of historical series are computed and shown below table.

[Table 4] Overall Contributions (\%)

\begin{tabular}{c|c|c|c}
\hline & GDP & Inflation Rate & Unemployment Rate \\
\hline 3 Productivity shocks & $24.80 \%$ & $55.28 \%$ & $63.52 \%$ \\
Leisure Preference shock & $11.00 \%$ & $16.03 \%$ & $32.52 \%$ \\
Intertemporal Preference shock & $36.91 \%$ & $6.03 \%$ & $1.24 \%$ \\
3 Foreign shocks & $23.75 \%$ & $13.57 \%$ & $2.44 \%$ \\
Monetary Policy shock & $3.31 \%$ & $9.04 \%$ & $0.21 \%$ \\
\hline
\end{tabular}

Substantial degree of contributions toward the GDP variations is not only due to domestic productivity shocks but also to intertemporal preference shock and foreign shocks. As mentioned earlier, this finding is consistent with Uribe and Yue (2006) which argues the significant influence of the country risk premium shock to emerging markets' business cycles. Inflation rate variations are mostly driven by productivity shocks and somewhat by leisure preference shock and foreign shocks. Lastly, it can be confirmed that the unemployment rate variations are largely attributed to domestic shocks rather than foreign shocks or intertemporal preference shock. 


\section{Conclusion}

A New Keynesian model with a labor friction in which involuntary unemployment can be endogenized is brought to estimation with the Korean macroeconomic data using a Bayesian estimation approach. In order to characterize the Korean labor market more realistically, the model is extended by specifying a small open economy with tradable and nontradable goods sectors. The results of empirical analyses based on the estimated model can be summarized as follows. First, it is confirmed that the sectoral reallocation of labors plays an important role in the adjustments of Korean labor market responding to some macroeconomic shocks. Particularly, employment in the tradable goods sector comoves positively with the foreign shocks while that in the nontradable goods sector do not. On the other hand, those changes in both sectors show symmetric dynamics in response to domestic shocks. Second, the historical decomposition analysis demonstrates that the cyclical fluctuations of unemployment in Korea are mostly explained by key domestic shocks such as domestic productivity shocks and preference shocks. A relatively small contribution of foreign shocks onto aggregate labor market variables is in part due to the sectoral shift of employment rather than changes in aggregate employment and labor force at extensive margins.

Admittedly, there are several limitations in this paper which are to be reserved for the future research. Some of them are particularly worth of discussions. First, as noted by Galí (2011b), the framework taken in this paper emphasizes the presence of noncompetitive wages via monopolistic market power of labor supply as a single source of unemployment. Consequently, the frictional unemployment which can be generated in search and matching frictions is missing in this model. Clearly, the dynamics of unemployment can be better described when two approaches are merged. Second, another limitation is associated with modeling the external shocks in a small open economy. For instance, the foreign interest rate is likely related to the foreign output and foreign inflation. Nevertheless, the model specifies the foreign shocks as possessing mutually independent processes. If there is a systematic relationship among foreign shocks, then the main findings of this paper should be revisited. 


\section{References}

Ahn, J. H. (2009), "A Comparative Analysis of the Employment Dynamics in the Manufacturing and the Service Industry: The Impact of Technical Progress and Business Cycle," Korean Journal of Labor Studies, 15(1), pp. 27-57 (in Korean).

An, S., T. Kang, G. Kim, and C. Choi (2013), "Macroeconomic and Financial Stability: DSGE Model Based Evidence from Korea," Mimeo, Bank of Korea.

An, S., and F. Schorfheide (2007), "Bayesian Analysis of DSGE Models," Econo-metric Reviews, 26(2), pp. 113-172.

Andreasen, M. M. (2010), "How to Maximize the Likelihood Function for a DSGE Model," Computational Economics, 35(2), pp. 127-154.

Blanchard, O., and J. Galí (2010), "Labor Markets and Monetary Policy: A New Keynesian Model with Unemployment," American Economic Journal: Macroeconomics, 2(2), pp. $1-30$.

Calvo, G. (1983), "Staggered Prices in a Utility-Maximizing Framework," Journal of Monetary Economics, 12(3), pp. 383-398.

Chari, V. V., P. J. Kehoe, and E. R. McGrattan (2002), "Can Sticky Price Models Generate Volatile and Persistent Real Exchange Rates?,” Review of Eco-nomic Studies, 69(3), pp. 533-563.

Choi, W. G., and Y. Wen (2010), "Dissecting Taylor Rules in a Structural VAR," IMF Working Paper WP/10/20, International Monetary Fund.

Christiano, L., M. Eichenbaum, and C. Evans (2005), "Nominal Rigidities and the Dynamic Effects of a Shock to Monetary Policy," Journal of Political Economy, 113(1), pp. 1.45 .

Christiano, L. J., M. Trabandt, and K. Walentin (2011): “Introducing Financial Frictions and Unemployment into a Small Open Economy Model," Journal of Economic Dynamics and Control, 35(12), 1999-2041.

Erceg, C. J., D. W. Henderson, and A. T. Levin (2000), "Optimal Monetary Policy with Staggered Wage and Price Contracts," Journal of Monetary Economics, 46(2), pp. 281313.

Faia, E. (2009), "Ramsey Monetary Policy with Labor Market Frictions," Journal of Monetary Economics, 56(4), pp. 570-581.

Galí, J. (2011a), “The Return of the Wage Phillips Curve," Journal of the European Economic Association, 9(3), pp. 436-461.

(2011b), Unemployment Fluctuations and Stabilization Policies: A New Keynesian Perspective, MIT Press.

Galí, J., F. Smets, and R. Wouters (2011), "Unemployment in an Estimated New Keynesian Model," NBER Macroeconomics Annual, 26, pp. 329-360.

Gertler, M., L. Sala, and A. Trigari (2008), “An Estimated Monetary DSGE Model with Unemployment and Staggered Nominal Wage Bargaining," Journal of Money, Credit and Banking, 40(8), pp. 1713-1764.

Gertler, M., and A. Trigari (2009), "Unemployment Fluctuations with Staggered Nash Wage Bargaining,” Journal of Political Economy, 117(1), 38-86. 
Iskrev, N. (2010), "Local Identification in DSGE Models," Journal of Monetary Economics, 57(2), pp. 189-202.

Justiniano, A., G. E. Primiceri, and A. Tambalotti (2010), "Investment Shocks and Business Cycles," Journal of Monetary Economics, 57(2), pp. 132-145.

Kim, T. B. (2014), "Analysis on Korean Economy with an Estimated DSGE Model after 2000," KDI Journal of Economic Policy, 36(2), pp. 1-64.

Lee, E. S., H. P. Park, S. J. Park, and J. Y. Kim (2013): "Analysis of Interindustry Labor Mobility and Implications," Monthly Bulletin, No. 2013-10, The Bank of Korea (in Korean).

Lee, J., and T.-D. Yeo (2008), "An Analysis of Korean Business Cycles with an Open Economy Bayesian DSGE Model," Journal of Korea Trade, 33(1), pp. 175-204.

Merz, M. (1995), "Search in the Labor Market and the Real Business Cycle," Journal of Monetary Economics, 36(2), pp. 269-300.

Mortensen, D. T., and C. A. Pissarides (1994), "Job Creation and Job Destruction in the Theory of Unemployment," Review of Economic Studies, 61(3), pp. 397-415.

Neumeyer, P. A., and F. Perri (2005), "Business Cycles in Emerging Economies: The Role of Interest Rates," Journal of monetary Economics, 52 (2), 345-380.

Rhee, J., and J. Song (2014), "Optimal Monetary Policy and Exchange Rate in a Small Open Economy with Unemployment," Journal of East Asian Economic Integration, 18(3), pp. 301-335.

Schmitt-Grohé, S., and M. Uribe (2003), “Closing Small Open Economy Models,” Journal of International Economics, 61(1), pp. 163-185.

Shimer, R. (2005), "The Cyclical Behavior of Equilibrium Unemployment and Vacancies," American Economic Review, 95(1), pp. 25-49.

Smets, F., and R. Wouters (2005), "Comparing Shocks and Frictions in US and Euro Area Business Cycles: A Bayesian DSGE Approach,” Journal of Applied Econometrics, 20(2), pp. 161-183.

Stockman, A. C., and L. L. Tesar (1995), "Tastes and Technology in a Two-Country Model of the Business Cycle: Explaining International Comovements," American Economic Review, 85(1), pp. 168-185.

Trigari, A. (2009), "Equilibrium Unemployment, Job Flows, and Inflation Dynamics," Journal of Money, Credit and Banking, 41(1), pp. 1-33.

Uribe, M., and V. Z. Yue (2006), "Country Spreads and Emerging Countries: Who Drives Whom?," Journal of international Economics, 69(1), pp. 6-36. 